\title{
Experimental and numerical study on fretting wear and fatigue of full-scale railway axles
}

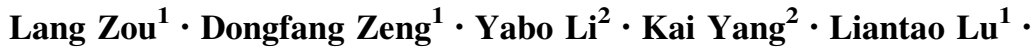 \\ Caiqin Yuan 1
}

Received: 7 August 2020/Revised: 21 October 2020/Accepted: 21 October 2020/Published online: 12 November 2020

(C) The Author(s) 2020

\begin{abstract}
This study investigated the fretting wear and fatigue of full-scale railway axles. Fatigue tests were conducted on full-scale railway axles, and the fretting wear and fretting fatigue in the fretted zone of the railway axles were analysed. Three-dimensional finite element models were established based on the experimental results. Then, multi-axial fatigue parameters and a linear elastic fracture mechanics-based approach were used to investigate the fretting fatigue crack initiation and propagation, respectively, in which the role of the fretting wear was taken into account. The experimental and simulated results showed that the fretted zone could be divided into zones I-III according to the surface damage morphologies. Fretting wear alleviated the stress concentration near the wheel seat edge and resulted in a new stress concentration near the worn/unworn boundary in zone II, which greatly promoted the fretting crack initiation at the inner side of the fretted zone. Meanwhile, the stress concentration also increased the equivalent stress intensity factor range $\Delta K_{\text {eq }}$ below the mating surface, and thus promoted the propagation of fretting fatigue crack. Based on these findings, the effect of the stress redistribution resulting from fretting wear is suggested to be taken into account when evaluating the fretting fatigue in railway axles.
\end{abstract}

Keywords Railway axle - Fretting wear - Fretting fatigue . Crack initiation $\cdot$ Crack propagation $\cdot$ Finite element

Dongfang Zeng

zengdongfang@swjtu.edu.cn

1 State Key Laboratory of Traction Power, Southwest Jiaotong University, Chengdu 610031, China

2 CRRC Qingdao Sifang Co., Ltd, Qingdao 266111, China

\section{Introduction}

The axle is a highly critical component of a railway vehicle [1-4]. Because it is connected to the wheels via pressfitting, the fretting wear and fretting fatigue usually appear within the region near the wheel seat edge [5-7]. When a crack reaches a critical size, the axle may break with a high risk of derailment. The design standards for railway axles estimate the nominal bending stresses in each section using the classical beam theory and prescribe axles to have an infinite life [8-12]. Nonetheless, the premature failure of a railway axle as a result of fretting fatigue still occasionally occurs. In 2016, fretting fatigue cracks were detected at the wheel seat of a certain type of locomotive axle used in China, leading to the replacement of more than 600 axles [13]. Obviously, the current design cannot fully ensure the safety of railway axles, and the fretting fatigue in railway axles should be further studied.

Because of the enclosed structure of a press-fitted axle, some fretting variables that influence the fretting characteristics, such as the local contact pressure and shear stress $[14,15]$, are hardly measured in fatigue tests. A numerical study is an alternative method for investigating the fretting fatigue in press-fitted axles. In the last few decades, elasticfatigue and elastoplastic-fatigue methodologies have been employed, in which elastic and elastoplastic material behaviours have been taken into account in the fatigue analysis, respectively $[16,17]$. However, neither of these two methodologies can reasonably explain some phenomena observed in failed axles, such as the crack initiation site being several to dozens of millimetres away from the wheel seat edge. Recently, the authors carried on fatigue tests using $13 \mathrm{~mm}$ diameter press-fitted axles, and found the profile evolution occurring at the press-fitted region as a result of fretting wear, from which fretting fatigue cracks 
initiated [18]. Based on the experimental observations, a wear-fatigue methodology was proposed to evaluate the fretting fatigue crack initiation in press-fitted axles, in which the effect of fretting wear was taken into account $[19,20]$. Nonetheless, the complex structure of a full-scale railway axle, such as the overhang of the wheel hub, transition fillet, and stress relief groove, cannot be considered for $13 \mathrm{~mm}$ diameter press-fitted axles. Furthermore, the nominal bending stress applied in a $13 \mathrm{~mm}$ diameter press-fitted axle was far greater than the actual stress on a railway axle. Both factors could influence the fretting fatigue crack initiation. Therefore, for full-scale railway axles, it is still necessary to investigate the fretting wear and its role in crack initiation.

In addition to the crack initiation, it is also important to gain knowledge about the fretting fatigue crack propagation in railway axles, which can then be used to determine the inspection intervals. Fracture mechanics methods have been used to analyse the fretting fatigue crack propagation in railway axles [3, 21-25]. Recently, Martínez et al. [22] and Erena et al. [25] used the extended finite element method (XFEM) to simulate crack propagation in pressfitted axles. Based on the Nasgro equation and concept of the cyclic R-curve, Pourheidar et al. [3] proposed a model to estimate the fretting fatigue crack propagation in fullscale railway axles with artificial micro-notches. Because of the fretting wear, the stress and strain states beneath the press-fitted region change with the evolution of the wear profile. It is expected that the crack propagation may also be influenced. However, the role of fretting wear in the fretting fatigue crack propagation in railway axles has not yet been studied.

In this study, experimental investigations were performed on a rotating bending test bench using full-scale railway axles. The damage in the fretted zone was observed and analysed, and the wear profiles were measured. Then, three-dimensional finite element (FE) models were established based on the obtained wear profiles. Subsequently, multi-axial fatigue parameters and a linear elastic fracture mechanics-based approach were employed to investigate the effects of the fretting wear on the fretting fatigue crack initiation and propagation in full-scale railway axles, respectively.

\section{Experimental procedure}

\subsection{Specimens and materials}

Figure 1 shows the geometrical configuration of the test axles. The detailed dimensions of the wheel seat and transition fillet are shown in Fig. 1b and c, respectively. The wheel seat and transition fillet were finished to provide them with a surface roughness of $R a=0.8 \mu \mathrm{m}$, and the other areas were finished to have a surface roughness of $R a=1.6 \mu \mathrm{m}$. Based on EN 13260 [26], the grip diameter $2 \Delta$ between the wheel and axle was set to $0.243 \mathrm{~mm}$.

The axle and wheel were made of EA4T and ER8 steels, respectively, which are widely used in high-speed railway wheelsets. The axle was first forged to a rough shape, and then heat treatments were conducted, including quenching and tempering. Thereafter, the axle was machined to the final shape as shown in Fig. 1. The mechanical properties of the axle and wheel materials are listed in Table 1.

\subsection{Fatigue tests}

The full-scale fatigue tests were performed on a Minden type test rig [27]. As shown in Fig. 2, the test rig was a cantilever resonant machine. The test axle was constrained using a clamp on one side, and an electric motor with a rotating imbalanced exciter was fixed on the opposite side. The test frequency was set as $17.5 \mathrm{~Hz}$.

Recent experimental studies found that the fatigue limit of a quench-tempered axle corresponding to a magnetic particle inspection (MPI) flaw detected at the wheel seat was approximately $70 \mathrm{MPa}$ [28]. Furthermore, the fatigue limit at the wheel seat of an EA4T hollow axle is $132 \mathrm{MPa}$ according to EN 13103 [8]. To simulate such stress levels, two axles were tested, and the nominal bending stresses at the wheel seat edge were set as 70 and $130 \mathrm{MPa}$, respectively. For simplicity, the axles with these nominal bending stresses of 70 and $130 \mathrm{MPa}$ were called Axles A and B, respectively.

EN 13103 [8] provides a method to determine the stress applied in the fatigue tests of full-scale railway axles. As shown in Fig. 3, two strain gauges were, respectively, applied in two measurement planes which were called Planes A and B, and then the corresponding nominal bending stress at the wheel seat edge could be calculated by extrapolation from the values measured by these strain gauges. During the fatigue tests, an ultrasonic inspection was performed every $10^{7}$ cycles, and the failure criterion was the appearance of a significant signal (2-10 mm crack) during the ultrasonic inspection. If no fretting fatigue crack was detected, the test was then restarted. The fatigue test was repeated until cracks were detected or the number of cycles reached $5 \times 10^{7}$ cycles. After the fatigue test, the axle was disassembled from the wheel, and an MPI was performed to further detect the fretting fatigue cracks.

After the MPI, specimens for detailed observations were cut out using a wire electrical discharge machine, and then ultrasonically cleaned with acetone for $20 \mathrm{~min}$. A stereo microscope (OLYMPUS-DSX100), scanning electron microscope (SEM, JSM-6610LV) and confocal laser scanning microscope (CLSM, OLYMPUS OLS4100) were 


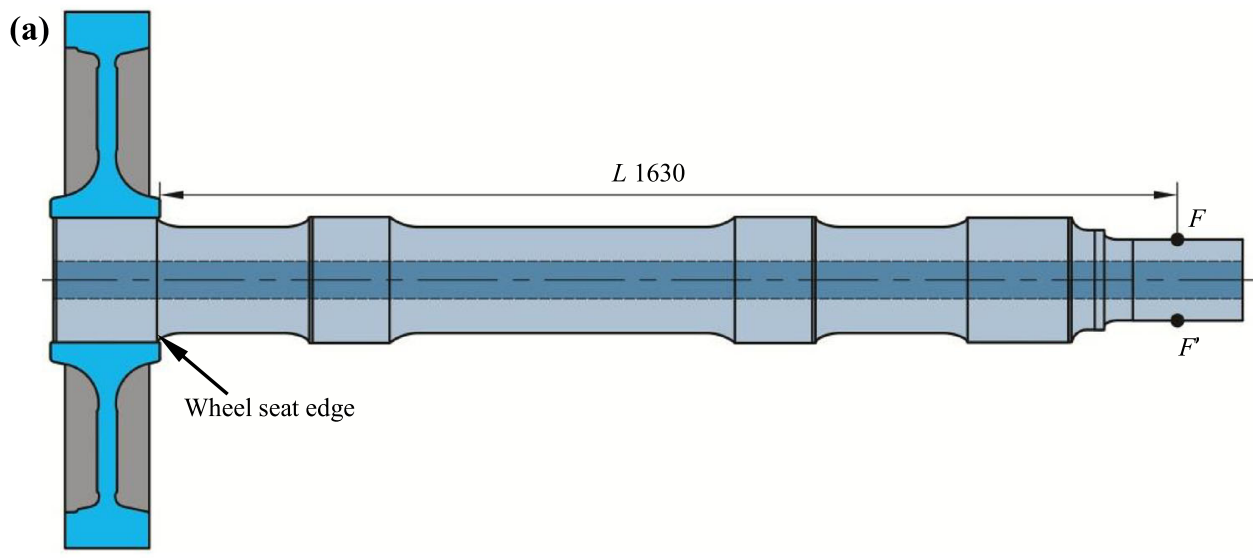

(b)

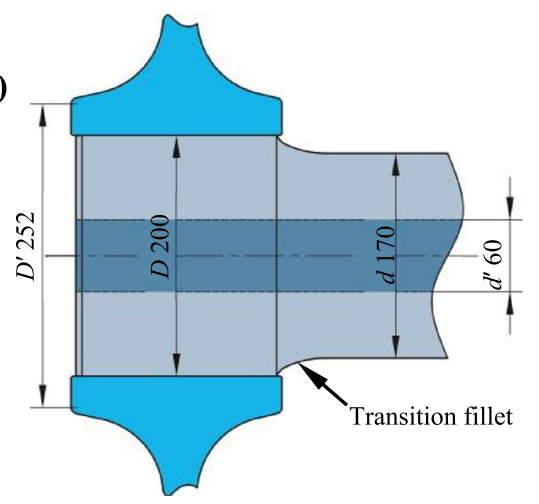

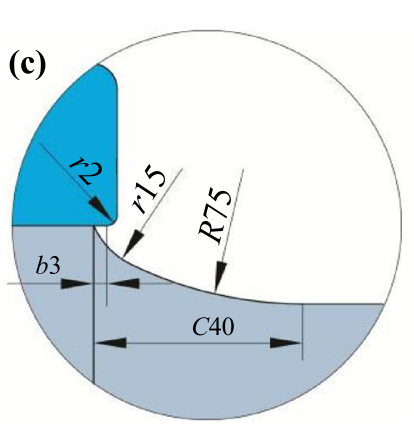

Fig. 1 Geometrical configuration of test axles: a overall geometry, b details of wheel seat, and $\mathbf{c}$ transition fillet (unit: $\mathrm{mm}$ )

Table 1 Mechanical properties of materials

\begin{tabular}{llllll}
\hline Materials & Elastic modulus $(\mathrm{GPa})$ & Poisson's ratio & Yield strength (MPa) & Tensile strength (MPa) & Microhardness, HV0.1 \\
\hline Axle & 210 & 0.28 & 552 & 689 & 252 \\
Wheel & 212 & 0.28 & 584 & 903 & 286 \\
\hline
\end{tabular}

used to observe the fretted damage surface. The chemical composition of the surface damage was analysed using energy dispersive X-ray spectroscopy (EDS, Oxford XMAX50 INCA-250). Furthermore, the wear profiles of both the axle and wheel were measured using the CLSM.

\section{Results and discussion}

\subsection{Fretting wear}

\subsubsection{Morphology of fretted zone}

For Axle A, the fatigue test was stopped when the number of loading cycles reached $5 \times 10^{7}$, and no fretting fatigue cracks were detected after the test. For Axle B, the fatigue test was stopped after $4 \times 10^{7}$ loading cycles because circumferential fretting fatigue cracks were detected.
Figure 4 shows the macroscopic morphology of the fretted zone after the test. As can be seen from Fig. 4a, two annular fretting damage strips were observed at the wheel seat of Axle A. The fretting damage strip near the transition fillet side was wider than that on the opposite side. This phenomenon was similar to that observed in failed axles $[6,15]$. Figures $4 \mathrm{~b}$ and $\mathrm{c}$ show macroscopic views of the fretting damage strips near the transition fillet sides of Axles A and B, respectively. The strip width for Axle A was approximately $20 \mathrm{~mm}$, whilst that for Axle B was approximately $39 \mathrm{~mm}$. Stereo microscope images of the regions indicated by the rectangles in Fig. $4 \mathrm{~b}$ and $\mathrm{c}$ are shown in Fig. 4d and e, respectively. Three characteristic damage zones, called zones I-III, were identified on the fretted surfaces of both axles. Each zone was distributed in a band shape along the axial direction. Zone I was narrow and clean, and was located near the wheel seat edge, where little wear debris was observed. Zone II was located deeper 


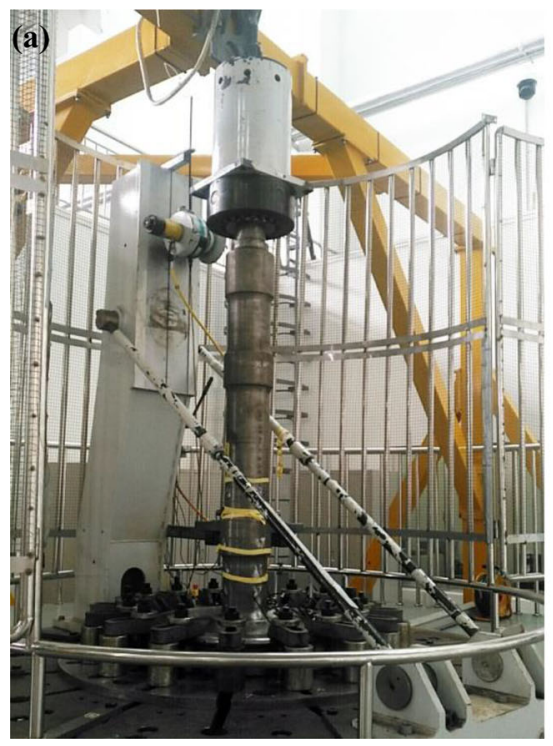

(b)

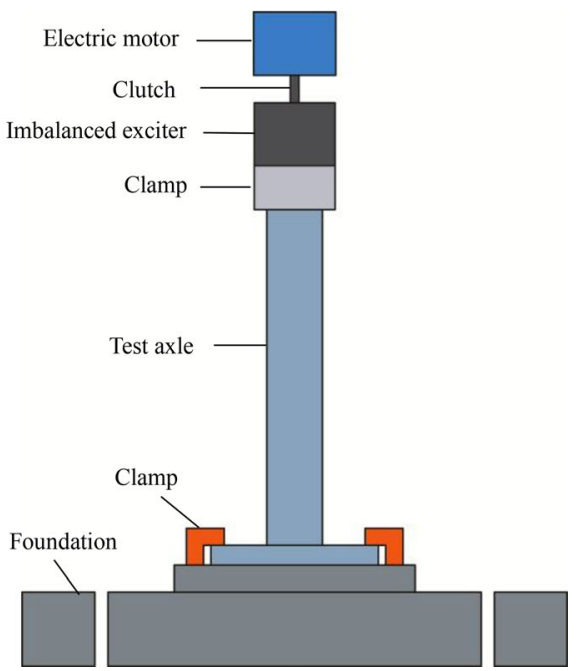

Fig. 2 Fatigue test rig: a Minden type test rig and $\mathbf{b}$ its principle sketch

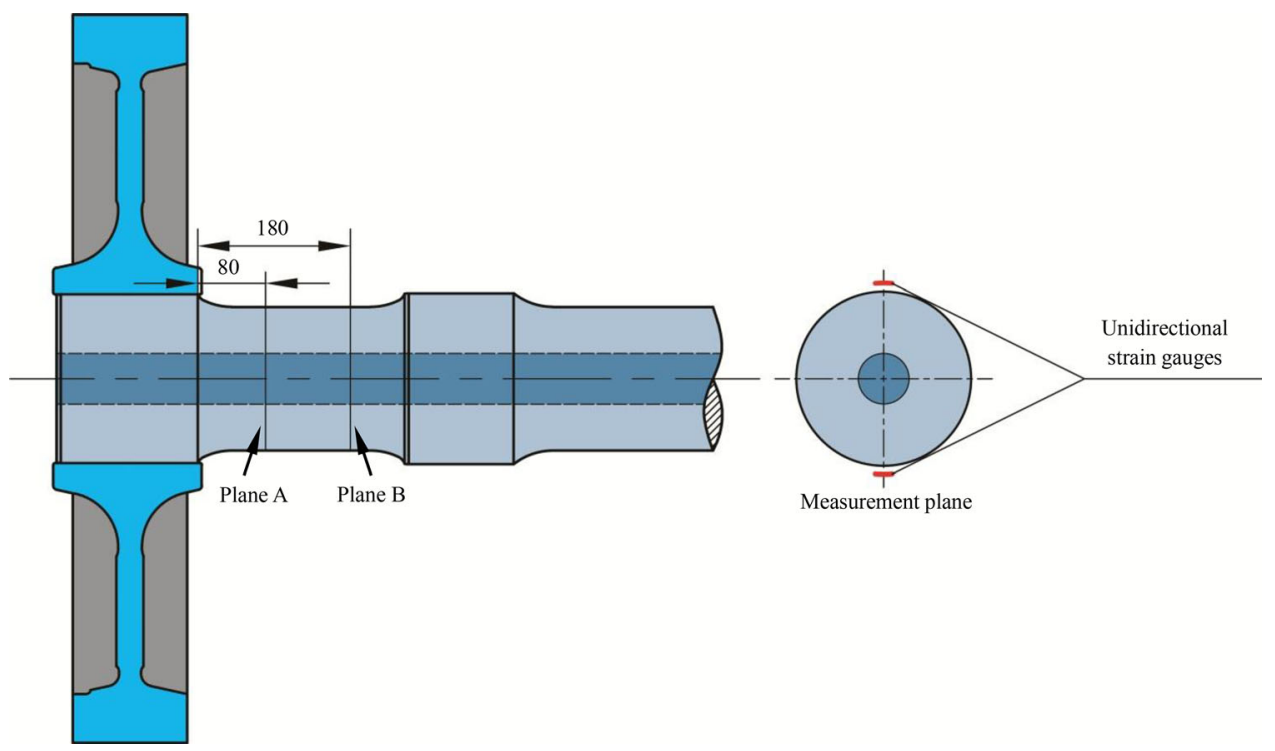

Fig. 3 Strain gauges and their positions on test axles (unit: $\mathrm{mm}$ )

into the fretted zone. It was black and reddish-brown in colour and severe surface damage could be observed. Because of the limitation of the stereo microscope, only part of zone III could be seen. The visible circumferential stripes observed on zone III were formed during the machining process for the axle, whilst the diagonal stripes were formed during the process of assembling and disassembling the axle. The left borders of zone III were located at the black dotted lines shown in Figs. 4b and c. A small amount of black debris was scattered in zone III, indicating that only slight fretting damage occurred. The widths of the damage zones were measured and listed in Table 2.
The detailed morphology of the fretted zone was analysed using the SEM equipped with EDS, as shown in Fig. 5. The analysis focused on Axle B because more severe fretting damage appeared on this axle. As shown in Fig. 5a, the rough surface of zone I indicates the occurrence of severe abrasive wear. The detected $\mathrm{O}$ signal was introduced by the internal oxidative debris. As depicted in Fig. 5b, some metallic flakes and material spalling were found in zone II, which was the characteristic of delamination. In addition to the black and reddish-brown wear debris observed in zone II (as seen in Fig. 4e), a remarkable $\mathrm{O}$ peak was also detected, indicating the occurrence of oxidative wear. Therefore, the main wear mechanisms in 

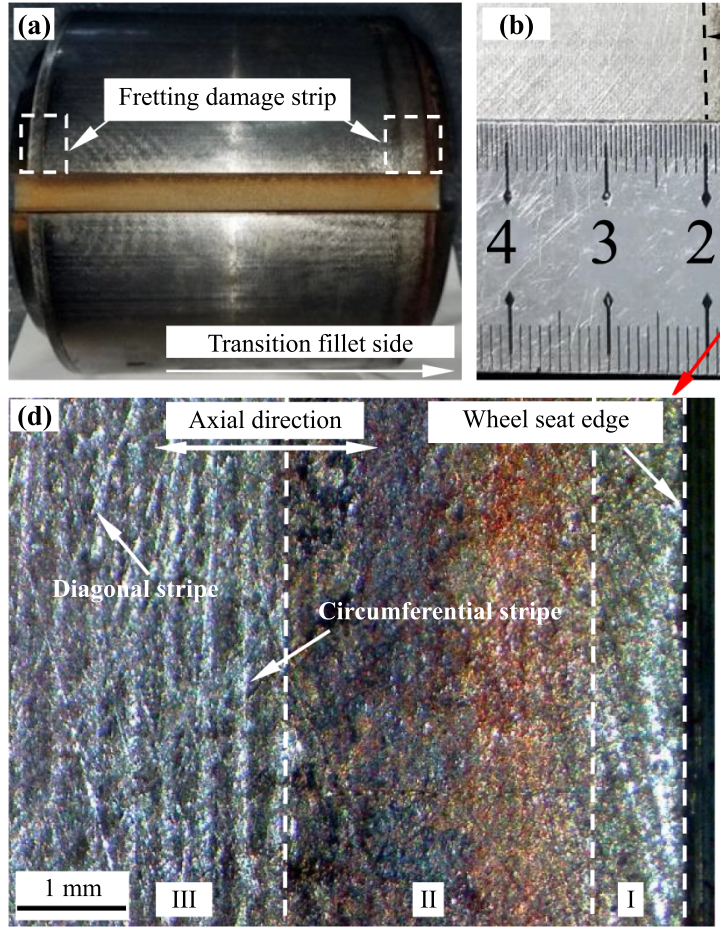
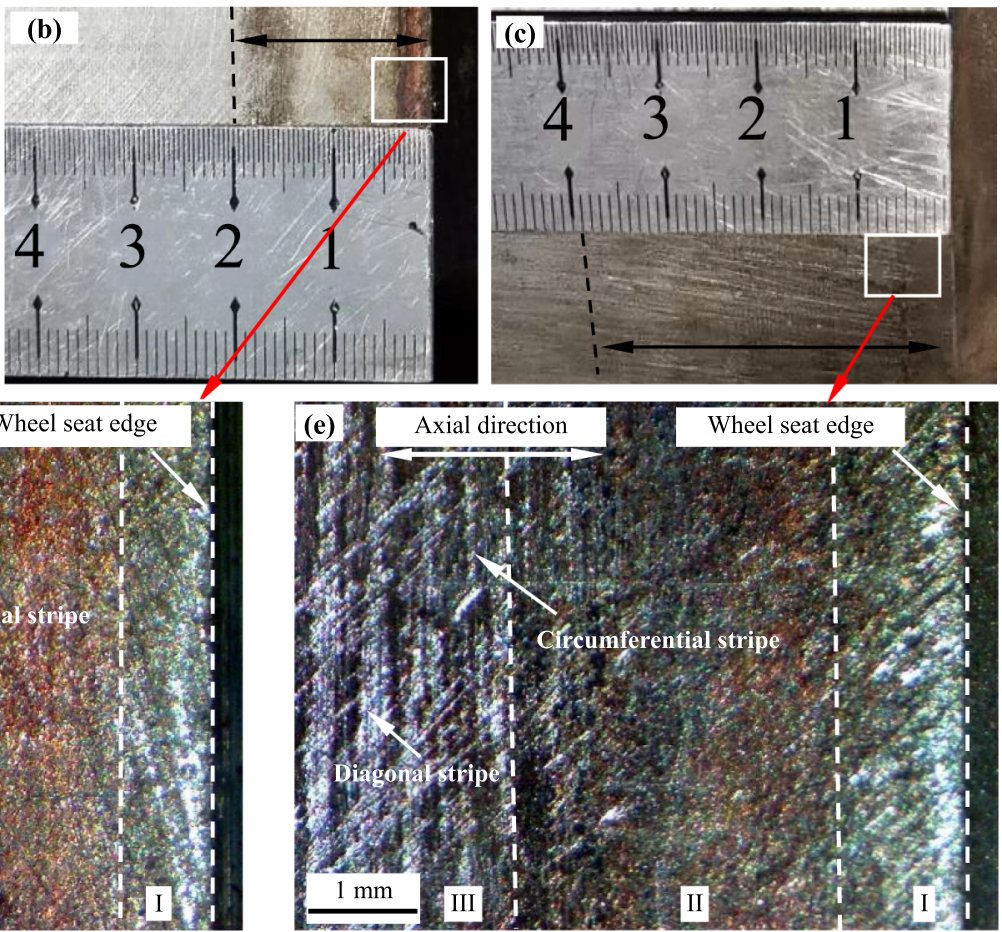

Fig. 4 Macroscopic morphology of fretted zone after fatigue test: a wheel seat of Axle A, macroscopic views of fretting damage strips observed on b Axle A and c Axle B, and stereo microscope images of fretted zones observed on d Axle A and e Axle B

Table 2 Width of each damage zone (mm)

\begin{tabular}{lllll}
\hline Axle & Zone I & Zone II & Zone III & Total width \\
\hline A & 0.8 & 2.8 & 16.4 & 20 \\
B & 1.3 & 3.4 & 34.3 & 39 \\
\hline
\end{tabular}

zone II were delamination and oxidative wear. Compared with zone II, a smaller number of metallic flakes and lower O peak were observed in zone III, as shown in Fig. 5d. This suggests that only slight delamination and oxidative wear occurred in zone III.

\subsubsection{Wear profiles}

Take Axle B as an example; Fig. 6 shows the process for measuring the wear profile of the fretted zone using CLSM. The 3D morphology of the damaged surface was observed, as shown in Fig. 6a. And then the 2D wear profile of the axle along the axial direction could be measured, as shown in Fig. 6b. 2D wear profiles were obtained at 24 sections for each test axle and wheel, and the mean value of these measured profiles was defined as the final wear profile, as shown in Fig. 7. The axle and wheel had similar wear profiles because they comprised a friction couple. The wear depth reached its maximum at the wheel seat edge, and then gradually decreased towards the inner side of the fretted zone. A comparison of the wear profiles of Axles A and B showed that the fretting wear that occurred in Axle B was more severe, even though it was subjected to fewer loading cycles. This phenomenon suggested that the loading stress level greatly affected the fretting wear. Furthermore, the worn/unworn boundaries of the two test axles were located within zone II.

\subsection{Fretting fatigue}

Fretting fatigue cracks were found in Axle B after $4 \times 10^{7}$ cycles, as shown in Fig. 8. A fretting fatigue crack was initiated approximately $4.1 \mathrm{~mm}$ away from the wheel seat edge, and the initiation site was located near the worn/ unworn boundary shown in Fig. 7b. It can be seen from Fig. $8 \mathrm{~b}$ that this crack initiated with an inclination of approximately $33^{\circ}$ relative to the depth direction of the axle, and the inclination angle gradually decreased with the propagation of the crack. A similar phenomenon has also been observed in failed railway axles $[3,7,15]$. 

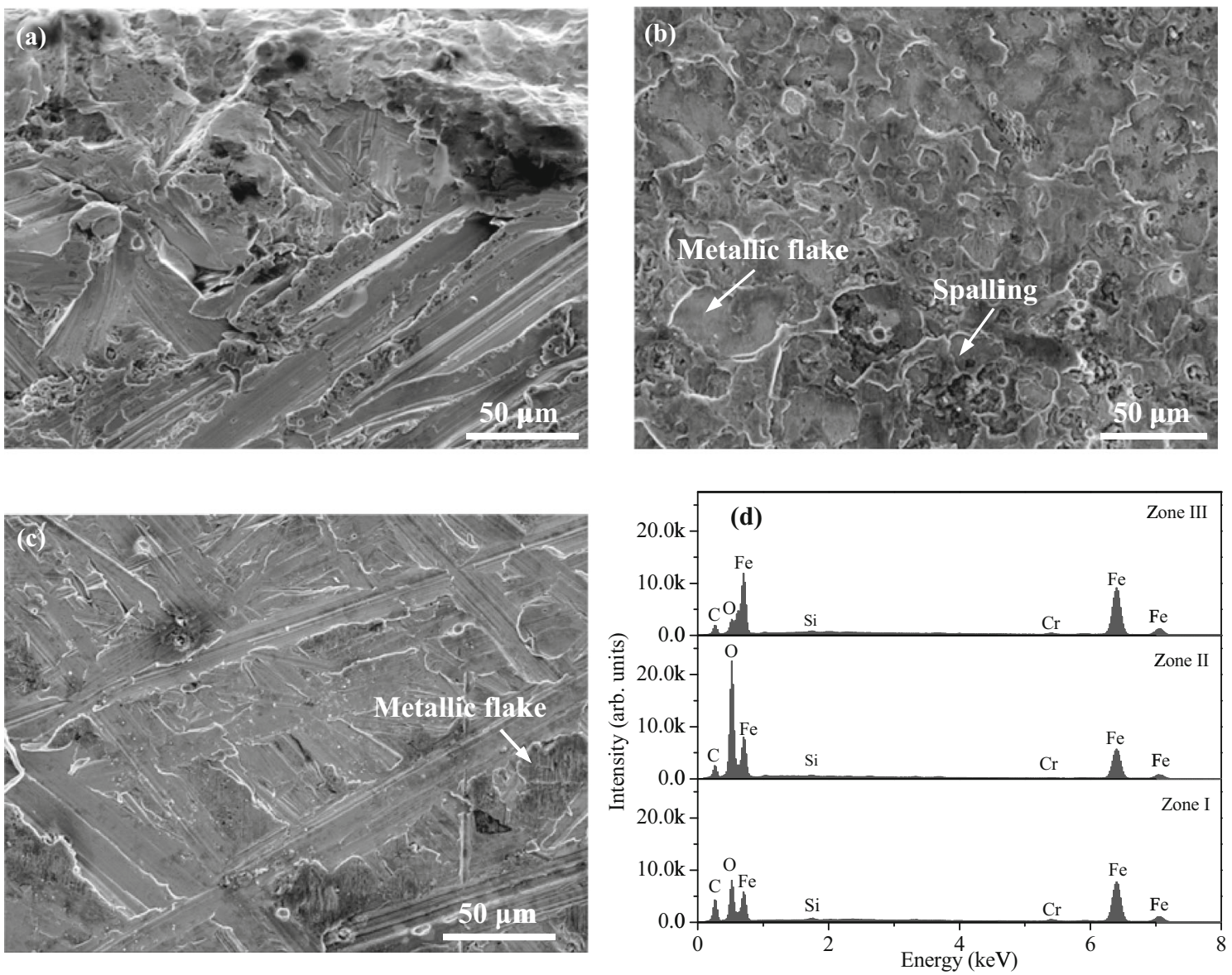

Fig. 5 SEM morphology and EDS analysis of fretted zone: a zone I, b zone II, c zone III and d EDS analysis

\section{Fretting fatigue evaluation}

\subsection{FE model}

Based on the geometrical configuration of the test axle shown in Fig. 1, the four FE models listed in Table 3 were established to investigate the effect of fretting wear on the fretting fatigue of full-scale railway axles. The FE preprocessor HYPERMESH was employed to create a starting 2D solid mesh of the test axle without considering fretting wear (models 1 and 3), as shown in Fig. 9a. A highly refined mesh size of $0.05 \mathrm{~mm}$ was selected in the areas of interest, including the regions near the wheel seat edge and transition fillet. Based on the measured wear profile shown in Fig. 7, a 2D solid mesh that considered the fretting wear (models 2 and 4) was then built by modifying the mesh node coordinates within the fretted zone, as shown in Fig. 9b. A 3D solid mesh was created by rotating the 2D solid mesh around the symmetry axis.

The 3D solid mesh was imported into the FE code ABAQUS, and the corresponding 3D FE model shown in Fig. 10 was obtained. The FE model was composed of three-dimensional eight-node linear brick elements (C3D8). The mating surface interaction between the axle and wheel was modelled via the master-slave contact algorithm, in which the wheel's inner surface was defined as the master surface whilst the wheel seat surface of the axle was the slave. The tangential behaviour was described using the basic Coulomb frictional model, and the coefficient of friction $(\mathrm{CoF})$ was set as 0.75 . The frictional constraints were modelled using the penalty algorithm, and the maximum elastic slip tolerance was set as 0.0001 . The optimisations of the mesh size, $\mathrm{CoF}$ and maximum elastic slip tolerance are described in Sect. 4.2.

In this study, the linear kinematic hardening model within ABAQUS [29] was used to consider the plastic deformation of the test axle resulting from contact. The yield stress $\sigma_{y}$ and hardening modulus of the EA4T steel were taken as $552 \mathrm{MPa}$ and $5.4 \mathrm{GPa}$, respectively, whilst they were taken as $584 \mathrm{MPa}$ and $8.0 \mathrm{GPa}$ for ER8 wheel steel, respectively.

The loading and boundary conditions imposed on the FE model corresponded to those for the test axle during the fatigue test. As shown in Fig. 10, the $x$-axis displacements 

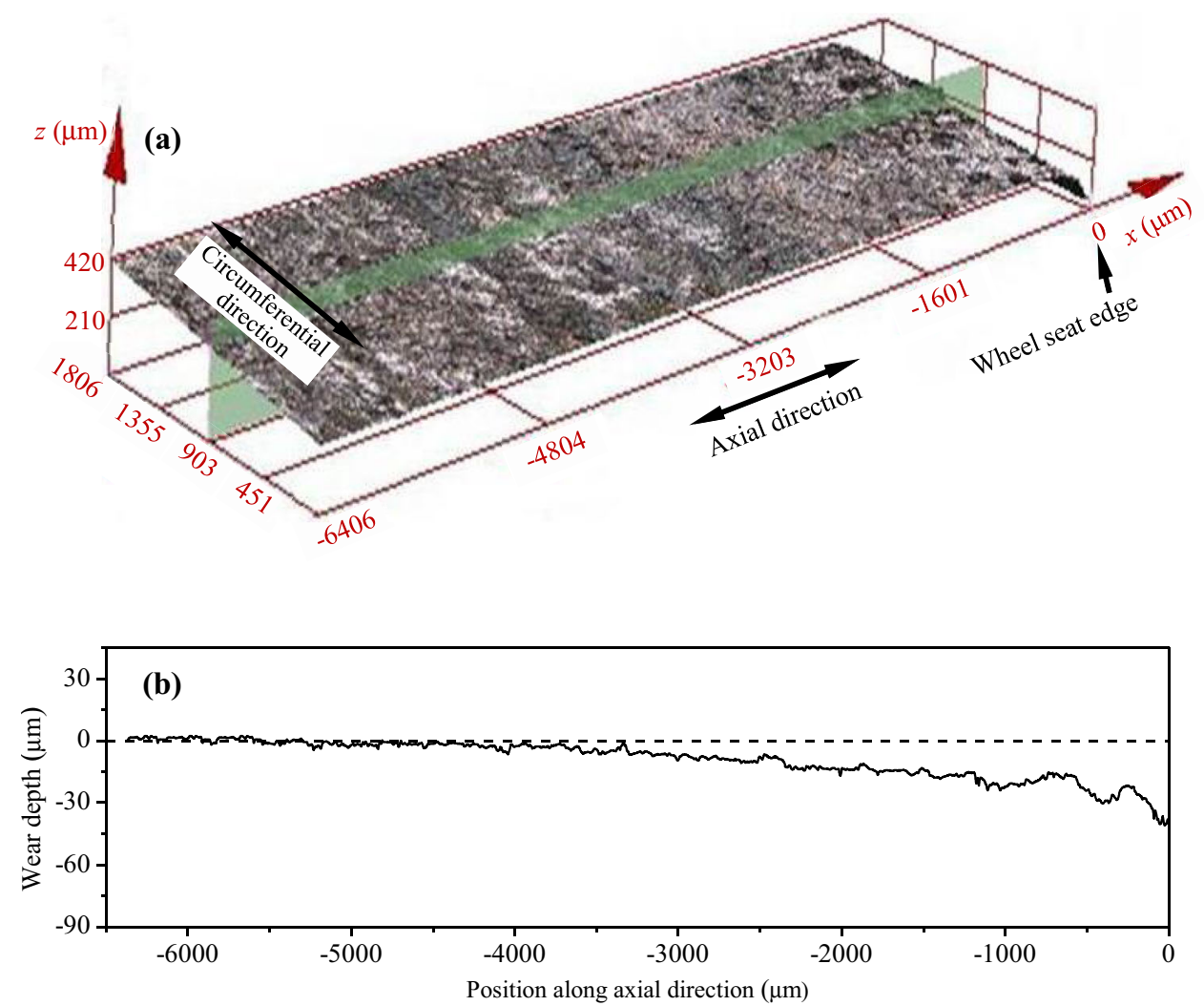

Fig. 6 Measurement process for profile of fretted zone using CLSM: a observation of damaged surface of Axle B and $\mathbf{b}$ wear profile indicated by green plane in (a)

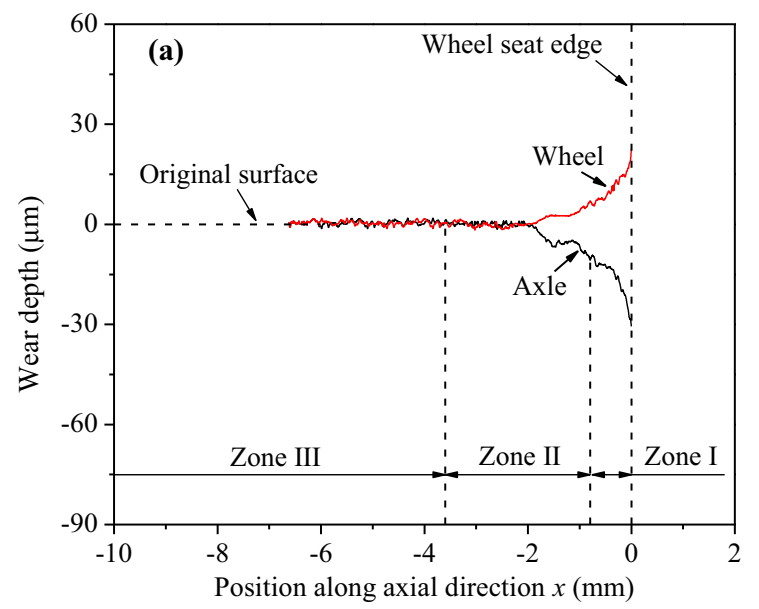

Fig. 7 Wear profiles of test axles: a Axle A and b Axle B

were restricted on the left surface of the wheel rim, and the external surface of the wheel was fixed. In step 1, an interference fit was introduced with a grip diameter of $2 \Delta=0.243 \mathrm{~mm}$, which equals to the interference used in the tested axle-wheel. In step 2, a concentrated force along the $y$-axis $\left(F_{y}=F_{0}\right)$ was applied at reference point $\mathrm{F}$. During the later steps, two computational time-varying

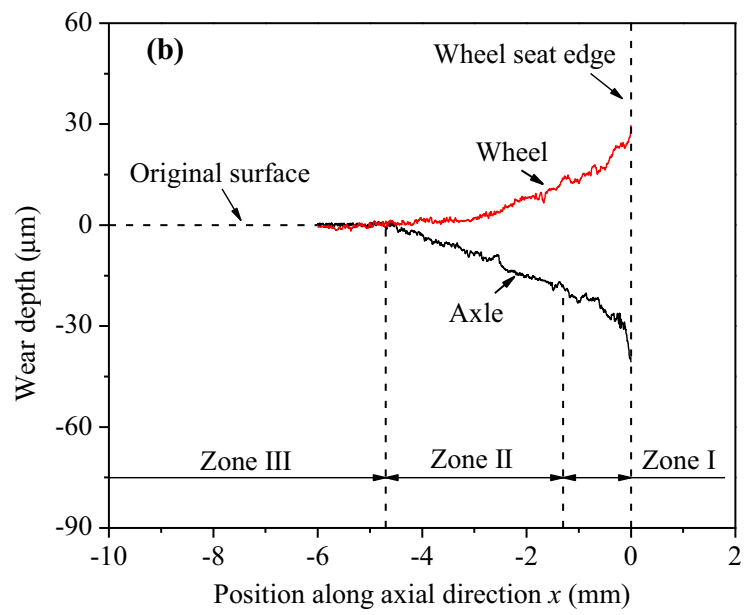

concentrated forces, $F_{y}=F_{0} \cos (2 \pi \mathrm{t})$ and $F_{z}=F_{0} \sin (2 \pi \mathrm{t})$, were applied at reference point $\mathrm{F}$ along the $y$ and $z$ axes, respectively. In this manner, a rotating bending stress was applied to the axle during the FE simulation. 

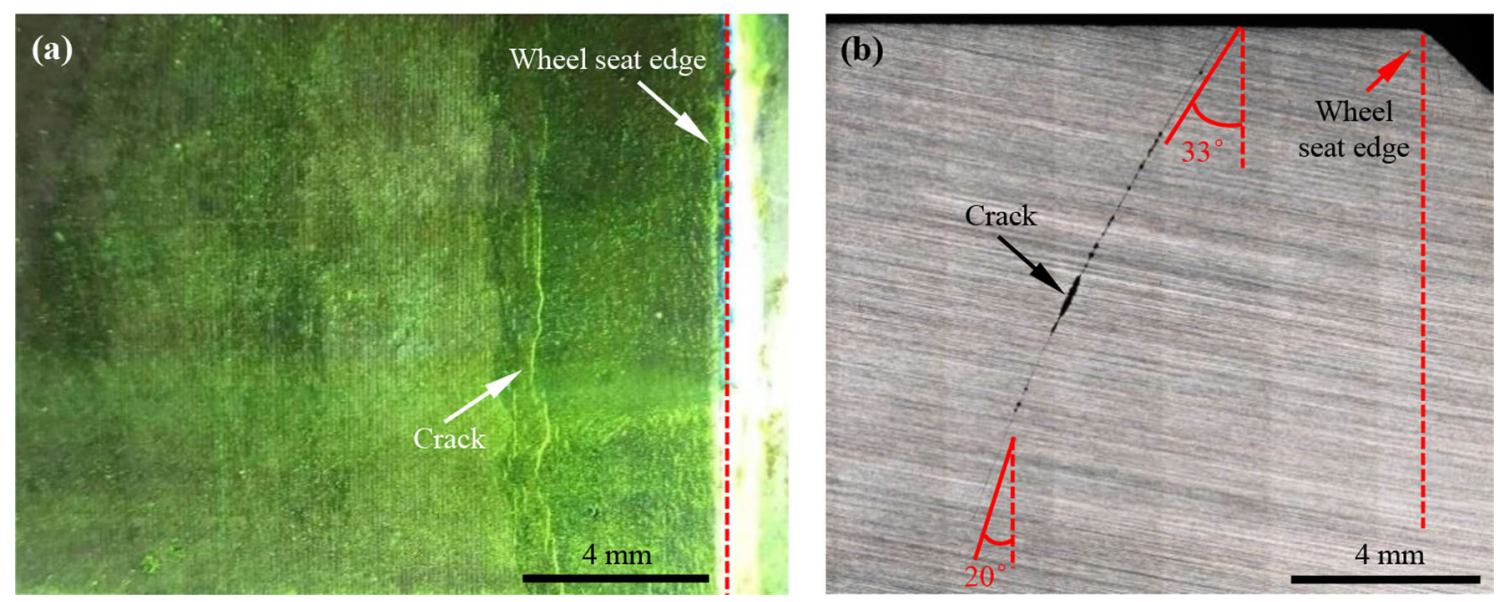

Fig. 8 Fretting fatigue cracks observed in Axle B: a mating surface and $\mathbf{b}$ cross-section

Table 3 FE models of test axles

\begin{tabular}{llc}
\hline Model & Wear profiles & Nominal bending stress (MPa) \\
\hline 1 & Unworn & 70 \\
2 & Worn & 70 \\
3 & Unworn & 130 \\
4 & Worn & 130 \\
\hline
\end{tabular}

\subsection{Optimisation of parameters}

\subsubsection{Mesh size near the wheel seat edge}

Figure 11 shows the effect of mesh size on the distribution of contact pressure near the wheel seat edge. It can be seen that the smaller mesh size can capture the more complicated variations in contact pressure near the wheel seat edge. When the mesh size is less than $0.05 \mathrm{~mm}$, the contact pressure almost remained unchanged, whilst the computational time increased rapidly. Therefore, the mesh size was set as $0.05 \mathrm{~mm}$ in this study.

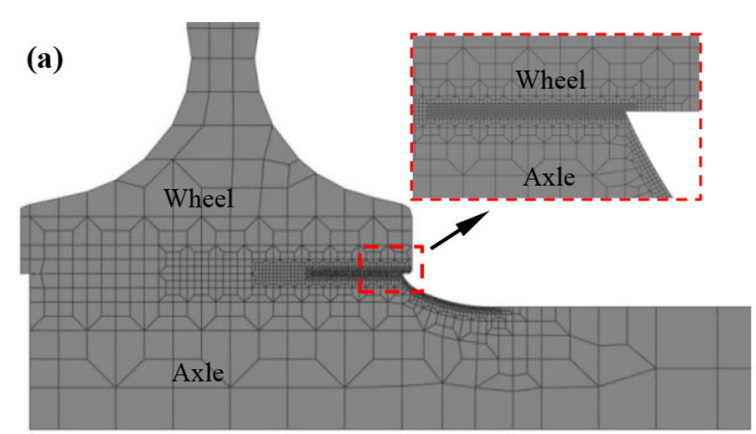

\subsubsection{Coefficient of friction}

The CoF of the test axle could not be measured via the fatigue test described in Sect. 2.2. Furthermore, it was unclear whether the $\mathrm{CoF}$ measured using the material fretting configurations, such as the ball-to-flat configuration [30], could be used for the FE simulation. In this study, the method described by Bertini and Santus [31] was used, in which the $\mathrm{CoF}$ value $\mu$ was determined by comparing the experimental result with the FE simulation result. The experimental slip lengths measured from the fretted zone of Axles A and B were 20 and $39 \mathrm{~mm}$, respectively. The slip lengths could also be acquired using the FE models that considered the fretting wear, as stated in Sect. 4.1. The relationships between the $\mathrm{CoF}$ values and simulated slip lengths are listed in Table 4. It can be seen that the simulated slip lengths were almost equal to the experimental slip lengths when the CoF value was set as $\mu=0.75$.

\subsubsection{Maximum elastic slip tolerance}

Different contact algorithms within ABAQUS can be used to describe the stick-slip behaviour at the mating surface of

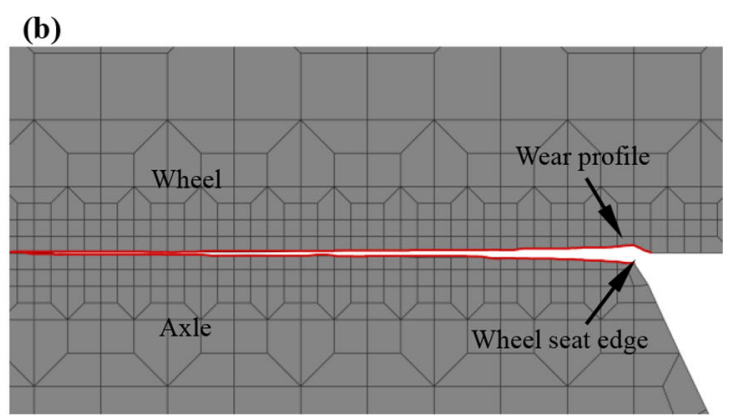

Fig. 9 FE mesh modelling: a 2D solid mesh without considering fretting wear and $\mathbf{b}$ 2D solid mesh considering fretting wear 


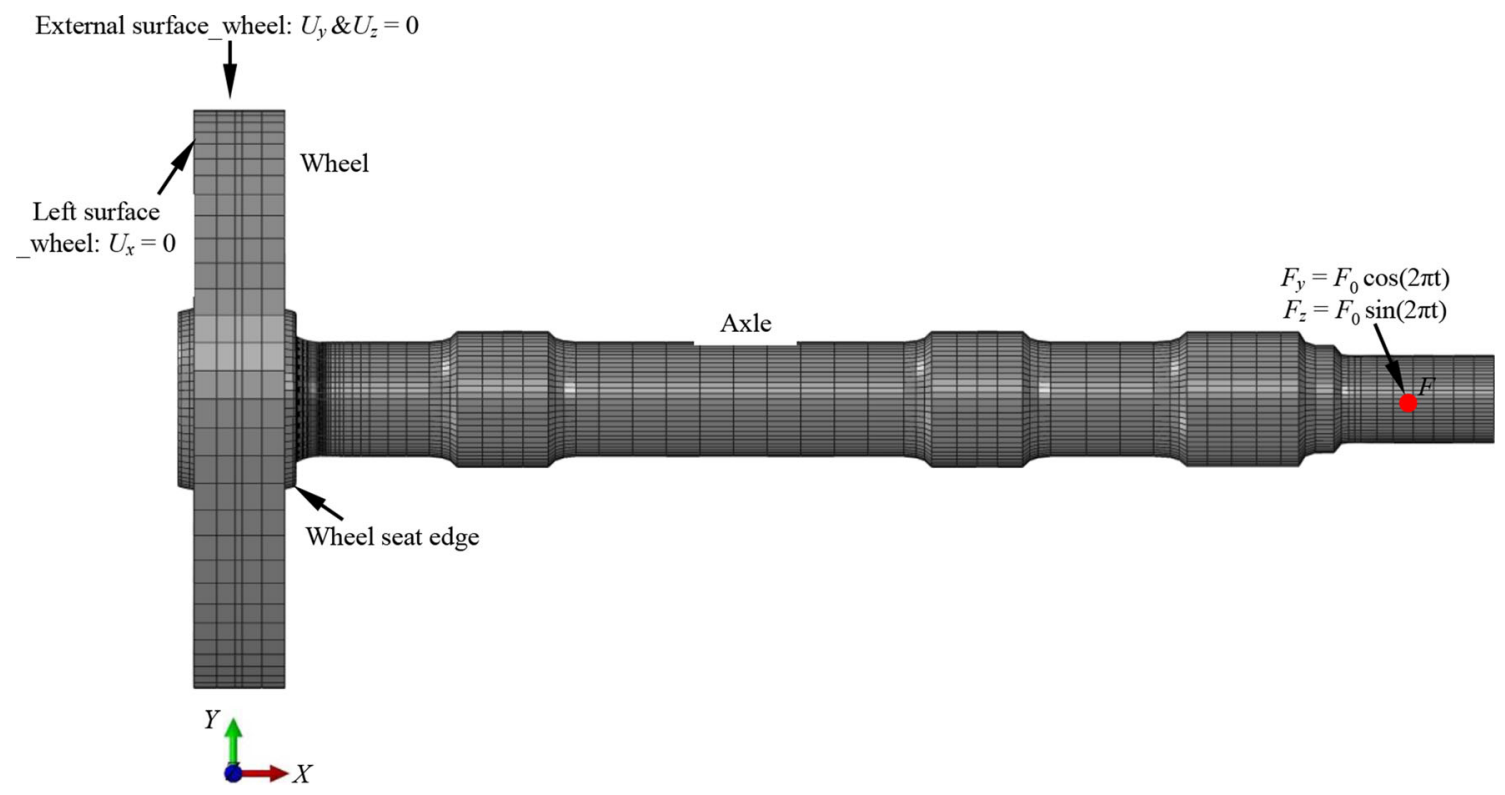

Fig. 10 FE model of test axle

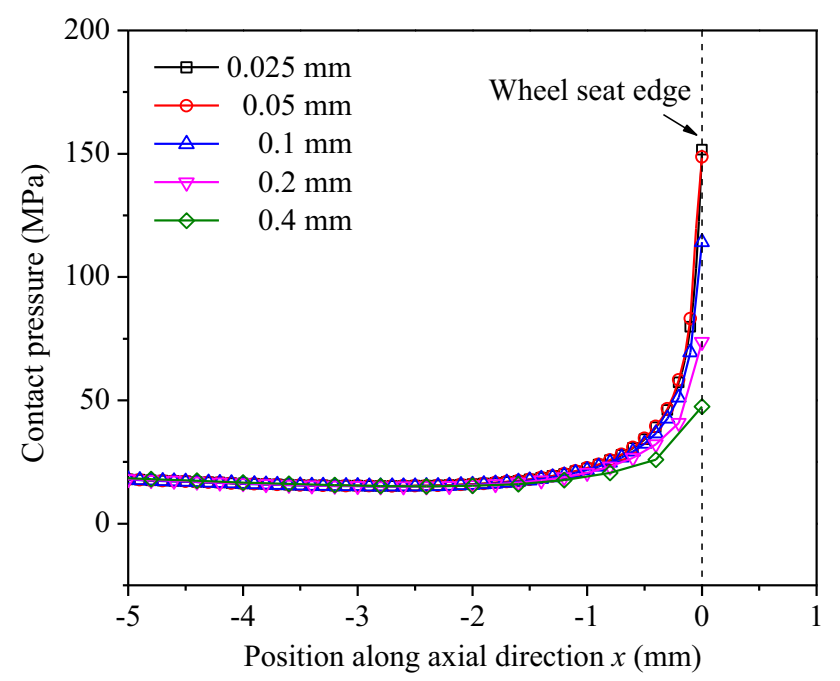

Fig. 11 Effect of mesh size on the distribution of contact pressure near the wheel seat edge

Table 4 Relationships between CoF values and simulated slip lengths

\begin{tabular}{lllllll}
\hline CoF & 0.6 & 0.65 & 0.7 & 0.75 & 0.8 & 0.85 \\
\hline Axle A & 26.8 & 24.6 & 22.4 & 20.6 & 19.0 & 17.5 \\
Axle B & 46.6 & 45.0 & 41.8 & 39.5 & 38.4 & 37.6 \\
\hline
\end{tabular}

a press-fitted axle. Rajasekaran et al. [32] found that the penalty approach with an appropriate maximum elastic slip tolerance could provide a result that was as good as that of the Lagrange multipliers approach, whilst avoiding the contact convergence problem. This study employed the penalty approach, and the distribution of the axial slip range with different slip tolerances is shown in Fig. 12. It can be seen that a smaller slip tolerance could provide a better description of the stick-slip, and the axial slip range gradually reached a stable state for a slip tolerance smaller than 0.0001. Because a smaller slip tolerance required a larger number of iterations, a value of 0.0001 was selected.

\subsubsection{Loading cycle}

Since the elastoplastic material model was used to consider the plastic deformation of the test axle resulting from contact, the stresses and strains used for crack initiation

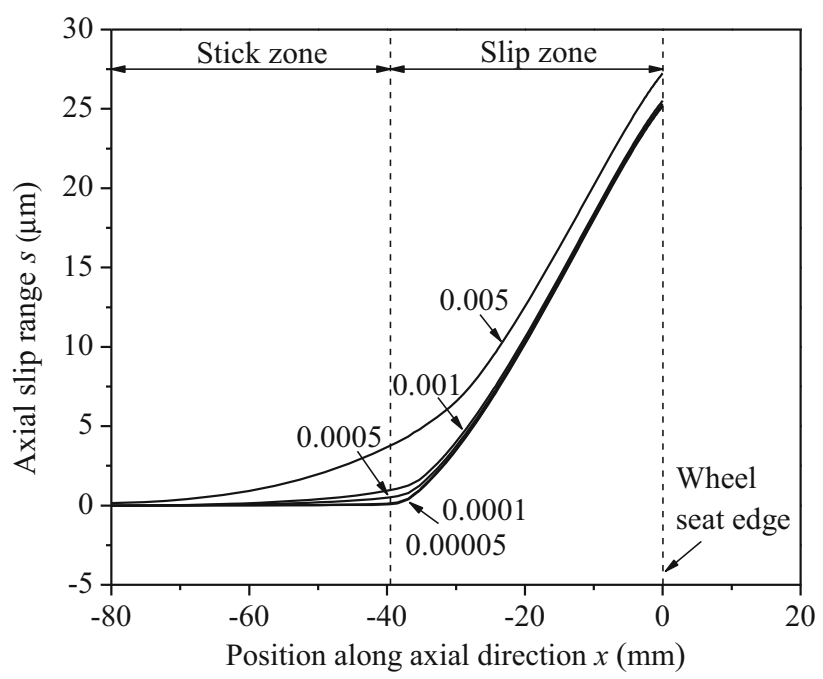

Fig. 12 Evolution of axial slip range $s$ of Axle B with maximum elastic slip tolerance 
evaluation should be taken from the loading cycle when the plastic deformation nearly reached a stable state. Figure 13 shows the evolution of the equivalent plastic strain PEEQ at the wheel seat edge with the loading cycles. It can be seen that PEEQ gradually increased in the initial loading cycles, and almost achieved steady after several loading cycles. To achieve the best compromise between the simulation accuracy and computational time, the stresses and strains obtained at the 40th loading cycle were used.

\subsection{Evaluation results}

\subsubsection{Stress analysis}

The stress distribution at the mating surface, including the contact pressure, frictional shear traction [14, 15], and von Mises stress, may be influenced by fretting wear. However, they could not be measured via fatigue tests because of the enclosed structure of a press-fitted axle. Therefore, the distributions of these stresses and the effects of fretting wear on these stresses were investigated using $\mathrm{FE}$ simulations.

Figure 14 shows the contact pressure distribution near the wheel seat edge when the cyclic axial bending stress is in tension. It can be seen that the distributions of the contact pressure were similar even if these two test axles were subjected to different loads. For the unworn axle, the contact pressure reached the maximum at the wheel seat edge, and then gradually decreased towards the inner side of the fretted zone. This simulation result was similar to that obtained by song et al. [15]. When the fretting wear occurred in the region near the wheel seat edge, material was removed and the grip diameter between the axle and wheel was reduced. Thereby, the mating surfaces near the

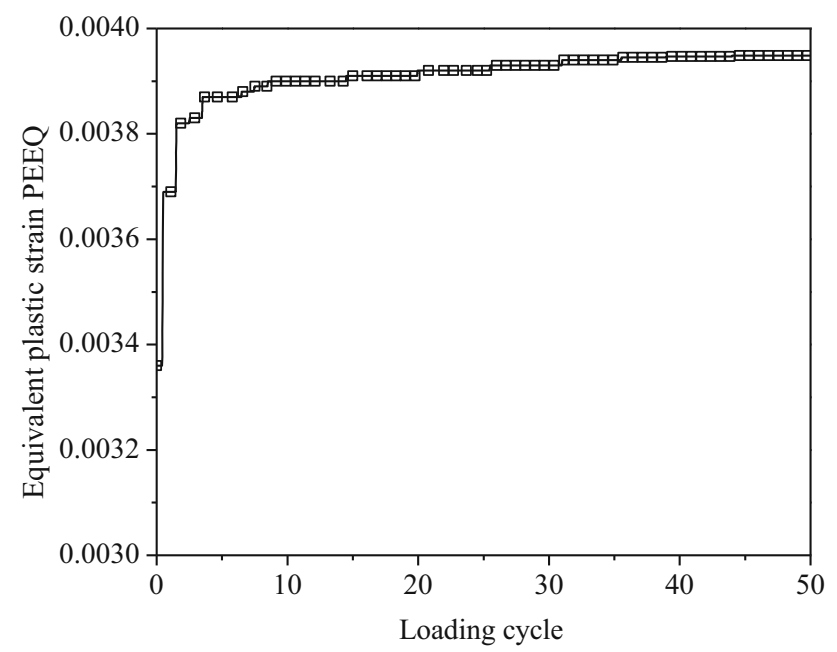

Fig. 13 Evolution of equivalent plastic strain PEEQ with the loading cycles wheel seat edge in the tension side were separated, and the corresponding contact pressure became null. An open zone appeared here, with its edge almost coinciding with the worn/unworn boundary located within zone II, as shown in Fig. 7. Because of the stress concentration induced by the material discontinuity, the peak value of contact pressure shifted from the wheel seat edge to the worn/unworn boundary. This phenomenon indicated that fretting wear changed the profile of the mating surface, thereby affecting the contact pressure distribution. The distribution of the frictional shear traction was similar to that of the contact pressure because they could be converted by the Coulomb friction law.

Figure 15 shows the von Mises stress contours of Axle $\mathrm{B}$ when the cyclic axial bending stress is in tension. The von Mises stress contours of Axle A were similar to those of Axle B. It can clearly be seen that the stress concentration near the wheel seat edge is relieved by the fretting wear, and new stress concentrations occur near the worn/ unworn boundary.

\subsubsection{Fretting fatigue crack initiation}

The investigation of the fretting fatigue crack initiation and propagation focused on Axle $\mathrm{B}$, where the fretting fatigue cracks were detected. Figure 16 shows the results of a stress analysis near the crack initiation site. It can be seen from Fig. 16a that stresses $S_{x z}$ and $S_{y z}$ remain nearly unchanged, stresses $S_{y y}$ and $S_{z z}$ are always negative, and the axial bending stress $S_{x x}$ and shear stress $S_{x y}$ vary significantly during a complete loading cycle. Obviously, the material in the fretted zone was mainly subjected to the multi-axial stress of $S_{x x}$ and $S_{x y}$, which resulted in the initiation of a fretting fatigue crack, as shown in Fig. 8. The loading path shown in Fig. 16b indicates that axial bending stress $S_{x x}$ and shear stress $S_{x y}$ are proportional.

It was unclear whether the fretting fatigue crack initiation in the press-fitted axle was dominated by the axial bending stress or shear stress. Therefore, this study used the Smith-Waston-Topper (SWT [33]) and Fatemi-Socie (F-S [34]) multi-axial fatigue parameters to evaluate the fretting fatigue crack initiation, which were suitable for tensile and shear cracking failure modes, respectively.

The SWT parameter is determined by the peak normal stress $\sigma_{n, \max }$ on the critical plane and maximum normal strain amplitude $\Delta \varepsilon_{\mathrm{n}, \mathrm{a}} / 2$ on the same plane during one complete loading cycle. It can be expressed as follows:

$\mathrm{SWT}=\sigma_{\mathrm{n}, \max } \frac{\Delta \varepsilon_{\mathrm{n}, \mathrm{a}}}{2}$.

The F-S parameter assumes that fatigue damage in a critical plane is promoted by the peak shear strain range $\Delta \gamma$ 

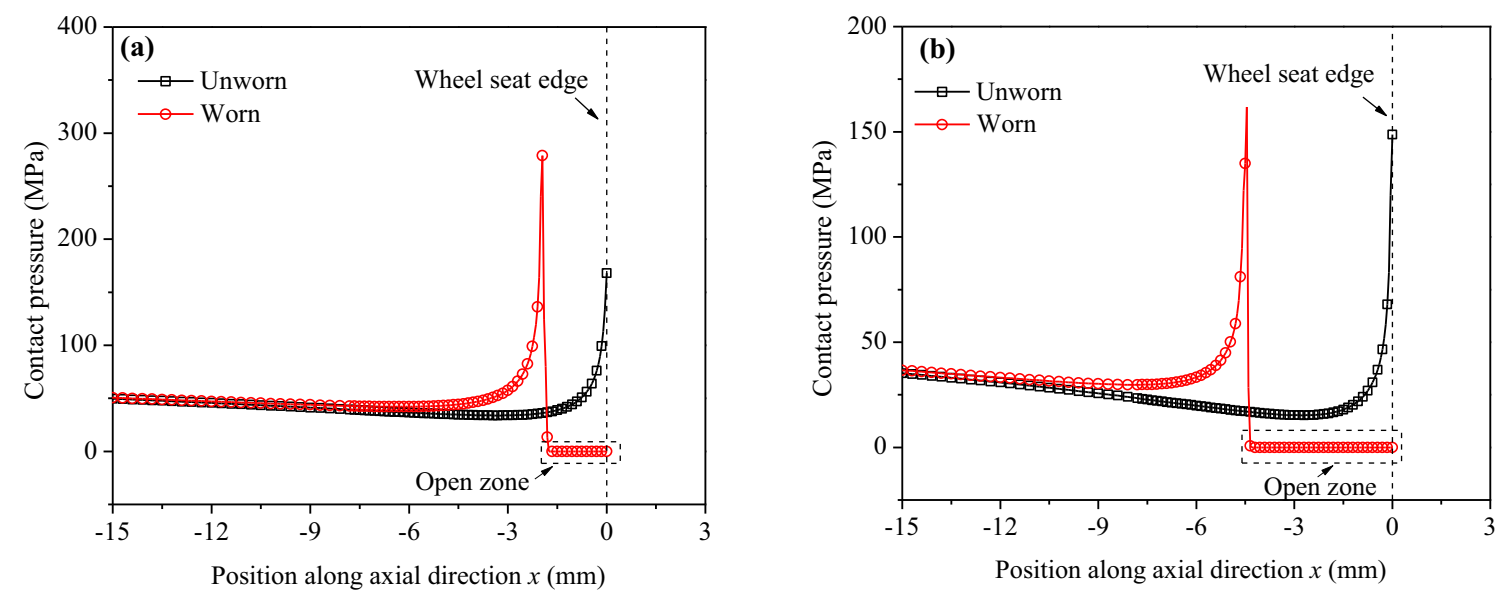

Fig. 14 Distribution of contact pressure near the wheel seat edge: a Axle A and $\mathbf{b}$ Axle B
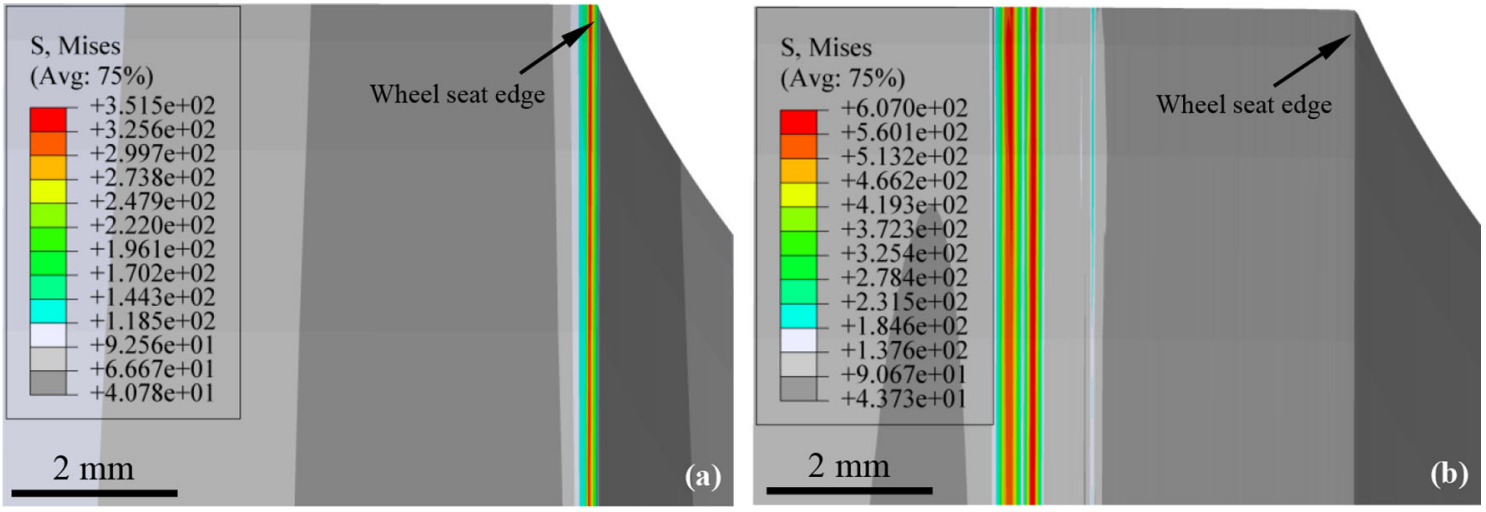

Fig. 15 Von Mises stress contours of Axle B: a without and $\mathbf{b}$ with consideration given to fretting wear
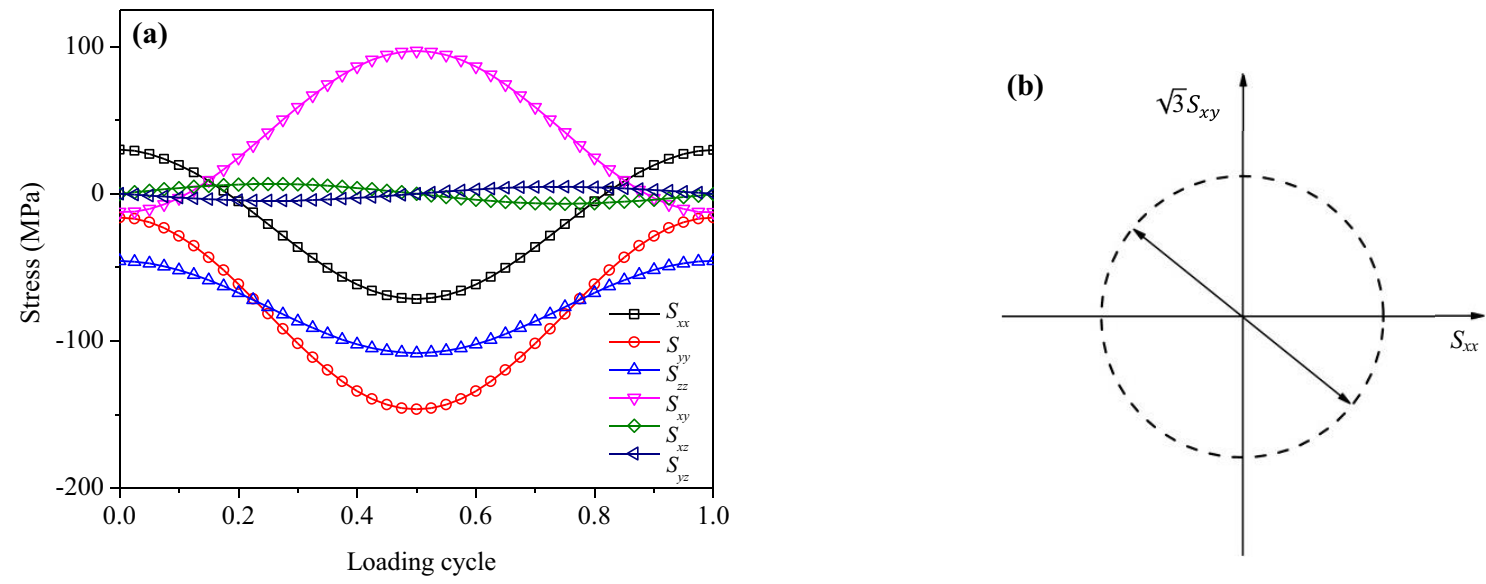

Fig. 16 Results of stress analysis near the crack initiation site: a loading history for a complete loading cycle and $\mathbf{b}$ loading path. These stresses were obtained at a surface point $4 \mathrm{~mm}$ away from the wheel seat edge 
and related maximum normal stress $\sigma_{\mathrm{n} \text {,max }}$. It can be expressed as follows:

$\mathrm{F}-\mathrm{S}=\frac{\Delta \gamma}{2}\left(1+\kappa \frac{\sigma_{\mathrm{n}, \max }}{\sigma y}\right)$,

where $\kappa$ is a material parameter that is determined by the interaction between the tensile and shear cracking failure modes, and is given a value of 0.3 for EA4T steel [35].

The SWT and F-S parameters were applied along with the critical plane approach [36], in which the multi-axial fatigue parameters were calculated for each candidate plane at various material points, and the maximum value of the parameter represented the damage at the evaluated material point.

Figure 17 shows the distributions of the SWT and F-S parameters near the wheel seat edge. It can be seen that, for the unworn axle, the maximum values of both the SWT and F-S parameters appear at the wheel seat edge, which implies that a fretting fatigue crack is most likely to be initiated here. This does not agree with the experimental result that a fretting fatigue crack was initiated approximately $4.1 \mathrm{~mm}$ away from the wheel seat edge. For the worn axle, the wear profiles of the axle and wheel were measured using CLSM, and the obtained wear profiles were not smooth, which caused three new stress concentrations in the fretted zone, as shown in Fig. 15b. Thereby, three peak values of the SWT and F-S parameters occurred in the inner side of the fretted zone, and the maximum value was approximately $4.4 \mathrm{~mm}$ away from the wheel seat edge. It can be found that when considering fretting wear, the locations of the maximum fatigue parameters are in good agreement with the observed crack initiation site.

In short, fretting wear near the wheel seat edge removed material and alleviated the stress concentration there. Meanwhile, it resulted in a new stress concentration occurring near the worn/unworn boundary. Under the action of continuous fretting wear, fretting fatigue cracks were eventually initiated at the inner side of the fretted zone.

\subsubsection{Fretting fatigue crack propagation}

As previously described, the fretting fatigue crack initiation was strongly influenced by the stress redistribution induced by fretting wear, and this stress redistribution could also influence the fretting fatigue crack propagation. Therefore, the stress intensity factors (SIFs) of fretting fatigue cracks with different depths shown in Fig. 8 were calculated with/ without considering the fretting wear, and then the effect of fretting wear on the crack propagation was evaluated.

The FE models 3 and 4 listed in Table 3 were employed in this section, and the SIFs at the crack tips were calculated by the use of the contour integrals. The material behaviours were idealised as being linear elastic, and the elastic modulus and Poisson's ratio values of the axle and wheel materials are listed in Table 1. During the simulation of fretting fatigue crack propagation in the press-fitted region, a crack is often simplified as a ring-shaped crack $[3,37]$. Considering the fact that the circumferential fretting fatigue crack observed in Axle B almost entirely encircled the axle, a ring-shaped crack was also used in the FE models. The pre-defined cracks with different depths shown in Fig. 18a were modelled as shown in Fig. 18b. The number of contours along the crack front was set as 15, and the maximum tangential stress (MTS) criterion was adopted. In this manner, the SIFs at the crack tips could be obtained at each increment during one complete loading cycle. Furthermore, the crack surfaces could contact due to the rotating bending stress. In such a case, the surface interaction between the crack surfaces was modelled via the self-contact algorithm, and both tangential and normal behaviours of the crack surfaces were guaranteed. The $\mathrm{CoF}$

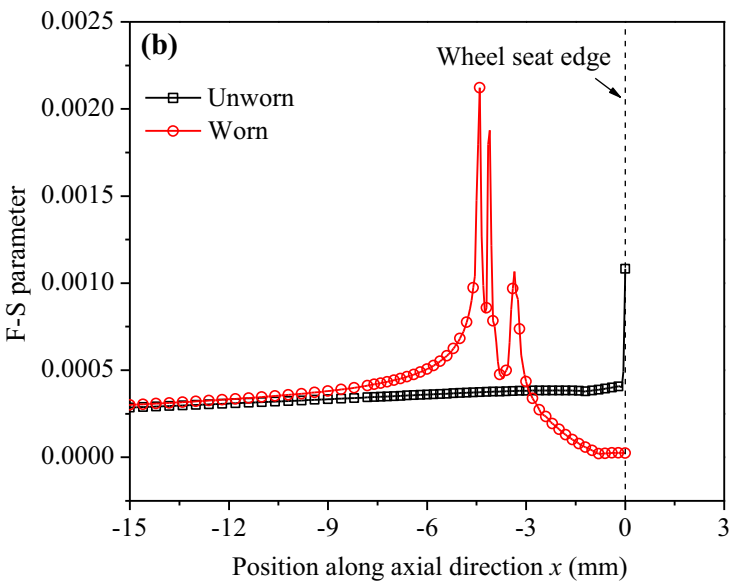

Fig. 17 Distributions of a SWT and b F-S parameters near wheel seat edge 
between the crack surfaces was set as 0.60 [38], whilst a hard contact algorithm was used to describe the normal behaviour. Therefore, the compressive pressure could be effectively transferred through the crack surfaces, by which the crack closure can be well simulated.

Figure 19 shows the SIF calculation process for the evaluation. The von Mises stress contours around a crack tip are shown in Fig. 19a, and the evolution of the SIFs with the number of contours is shown in Fig. 19b. The SIFs oscillate slightly in the first contour, after which they converge. Therefore, the average SIFs obtained from contours $2-15$ were used to evaluate the crack propagation.

Figure 20 shows the evolution of the SIFs for the crack shown in Fig. 19 during a complete loading cycle. Since the negative $K_{\mathrm{I}}$ resulting from the negative bending stress has little influence on the crack propagation, it was not taken into account in this study according to the data processing method adopted by Mai et al. [39]. It can be seen that the minimum value of $K_{\mathrm{I}}$ is null, $K_{\mathrm{II}}$ varies a little within a complete loading cycle, and $K_{\text {III }}$ remains almost unchanged. The experimental crack propagation path shown in Fig. 8 indicates that the crack propagates in a I-II mixed mode. Therefore, an equivalent SIF range $\Delta K_{\mathrm{eq}}$ was introduced to simultaneously consider the effects of the axial bending and shear driving forces $\left(\Delta K_{\mathrm{I}}\right.$ and $\left.\Delta K_{\mathrm{II}}\right)$ on the fretting fatigue crack propagation. $\Delta K_{\text {eq }}$ can be expressed as follows:

$\Delta K_{\text {eq }}=f\left(\Delta K_{\mathrm{I},} \Delta K_{\mathrm{II}}\right)$

where $\Delta K_{\mathrm{I}}=K_{\mathrm{I}, \max }-K_{\mathrm{I}, \min }$ and $\Delta K_{\mathrm{II}}=K_{\mathrm{II}, \max }-K_{\mathrm{II}, \min }$.

Various $\Delta K_{\mathrm{eq}}$ models have been proposed to investigate the fatigue crack propagation in a I-II mixed model [40-44]. Previous studies have shown that these $\Delta K_{\mathrm{eq}}$ models give similar prediction results [45, 46]. Here, Richard's model $[42,43]$ was employed, which can be expressed as follows:
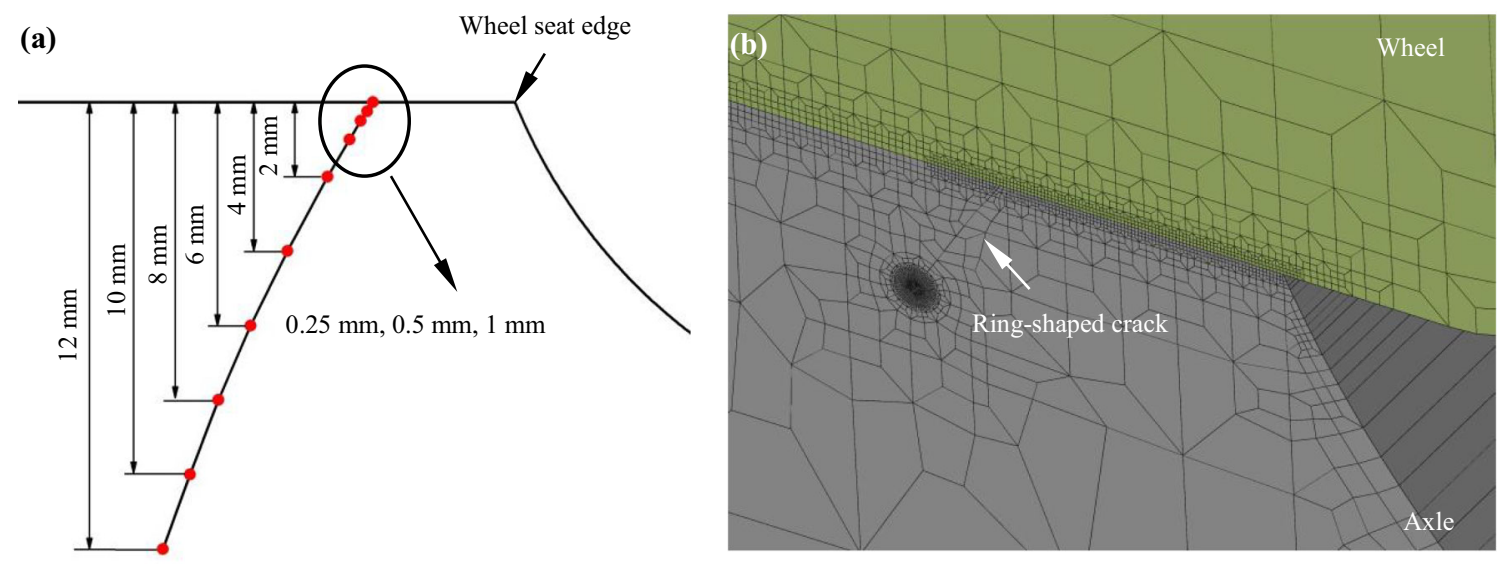

Fig. 18 Crack configuration: a fatigue crack propagation path and $\mathbf{b}$ crack with a depth of $2 \mathrm{~mm}$ modelled in the FE model
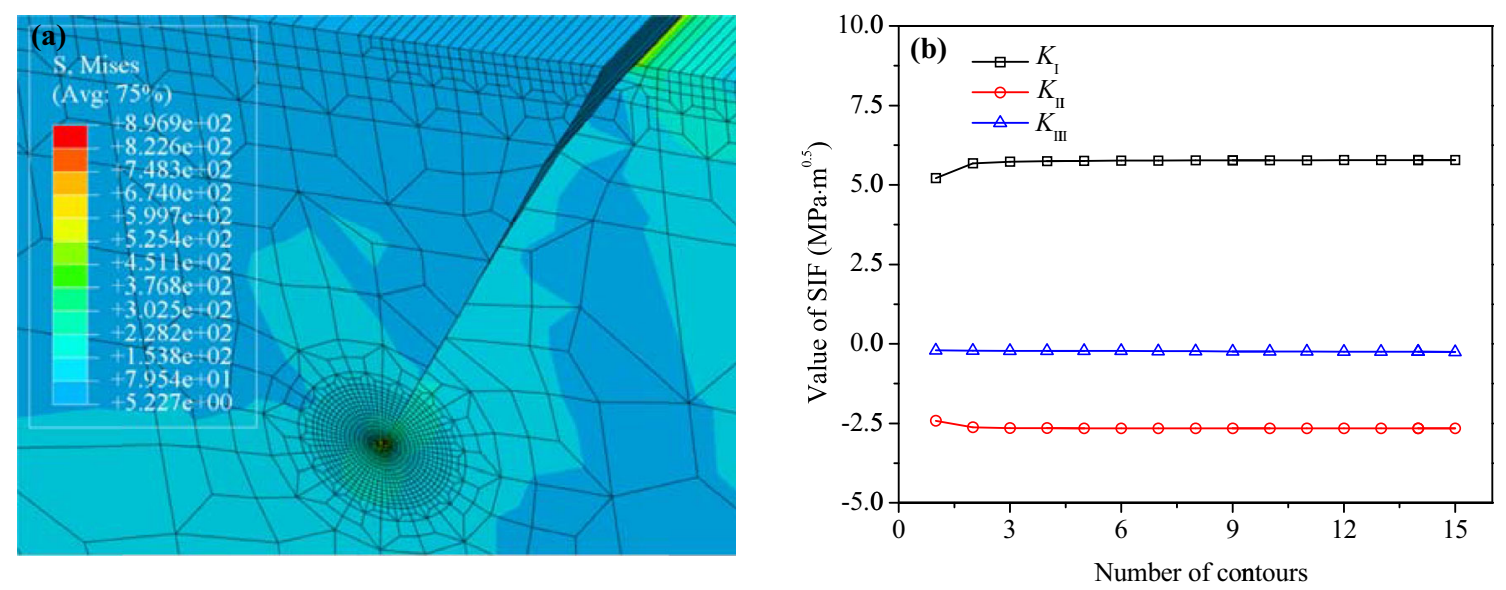

Fig. 19 SIF calculation process for evaluation: a von Mises stress contours around crack tip and $\mathbf{b}$ evolution of SIFs with number of contours 
$\Delta K_{\text {eq }}=\frac{\Delta K_{\mathrm{I}}}{2}+\frac{1}{2} \sqrt[4]{\Delta K_{\mathrm{I}}^{2}+4\left(\beta \Delta K_{\mathrm{II}}\right)^{2}}$,

where $\beta=1.155$ is a constant [47].

Figure 21 shows the evolution of the SIF ranges $\Delta K_{\mathrm{I}}$ and $\Delta K_{\text {II }}$ with the crack depth. It can be seen that, for the worn/ unworn axles, the $\Delta K_{\mathrm{I}}$ value increases with an increase in the crack depth, whilst the $\Delta K_{\text {II }}$ value remains nearly unchanged. These simulation results indicate that the crack propagation in mode I plays a more critical role as the crack propagates, which can be used to explain the observed phenomenon shown in Fig. 8 that the crack propagation angle gradually decreases with an increase in the crack depth. As shown in Fig. 21a, for a crack depth of 0-2 mm, the $\Delta K_{\mathrm{I}}$ value calculated for the worn axle is greater than that for the unworn axle. The $\Delta K_{\mathrm{I}}$ values

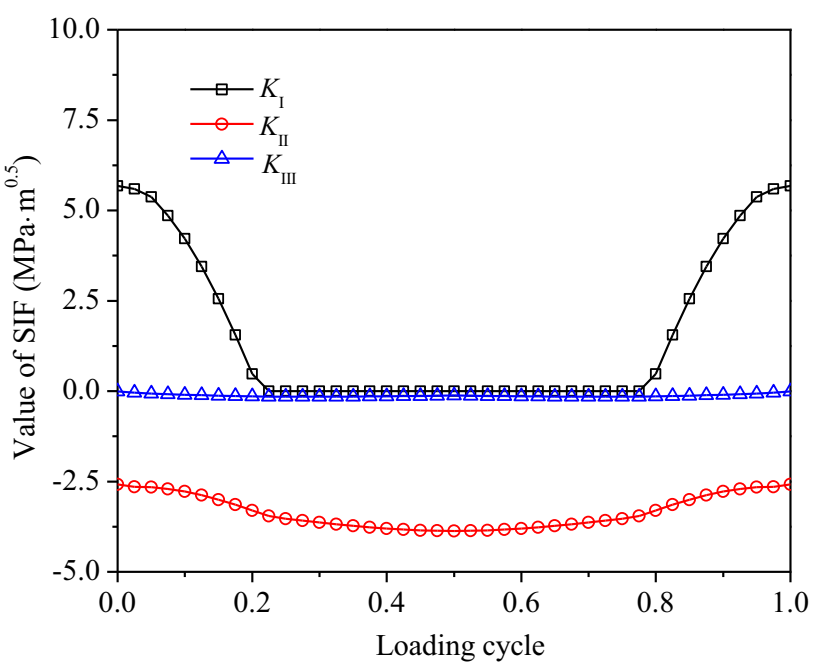

Fig. 20 Evolution of SIFs for crack with a depth of $2 \mathrm{~mm}$ during a complete loading cycle

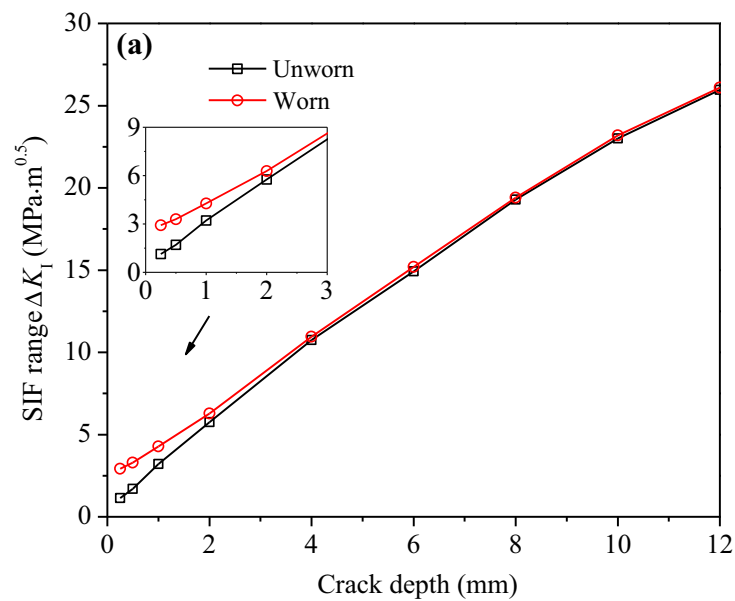

calculated for the worn/unworn axles are almost identical when the crack depth exceeds $2 \mathrm{~mm}$. As depicted in Fig. $21 \mathrm{~b}$, the $\Delta K_{\mathrm{II}}$ value calculated for the worn axle is always slightly less than that for the unworn axle.

In this study, $\Delta K_{\mathrm{I}}$ is mainly determined by the maximum axial bending stress $S_{x x \text {, max }}$ and crack depth. The distributions of $S_{x x, \max }$ along the depth direction were calculated, as shown in Fig. 22. For the unworn axle, the effect of press-fitting decreases with an increase in depth, resulting in an increase in $S_{x x \text {,max }}$. For the worn axle, the material discontinuity resulting from the fretting wear introduces a stress concentration near the worn/unworn boundary, and the effect of the stress concentration decreases with an increase in depth. The combined effect of press-fitting and stress concentration causes $S_{x x \text {, max }}$ to decrease near the mating surface, and then increase with an increase in depth. The value of $S_{x x, \max }$ calculated for the worn axle within the region of $0-2 \mathrm{~mm}$ is greater than that for the unworn axle, which results in a difference between the calculated $\Delta K_{\mathrm{I}}$ values of the worn and unworn axles. When the crack depth exceeds $2 \mathrm{~mm}$, the small difference in $S_{x x, \max }$ has little influence on the $\Delta \mathrm{K}_{\mathrm{I}}$ values calculated for the worn/unworn axles. Since $\Delta K_{\mathrm{II}}$ is strongly affected by the frictional contact between the crack surfaces, it is difficult to explain the evolution trend of $\Delta K_{\mathrm{II}}$ shown in Fig. $21 \mathrm{~b}$ using a simple stress distribution.

The evolution of both the equivalent SIF range $\Delta K_{\mathrm{eq}}$ and the relative error $\delta$ with the crack depth is shown in Fig. 23. The relative error $\delta$ between the calculated equivalent SIF range $\Delta K_{\text {eq }}$ for the worn and unworn axles is defined as

$\delta=\frac{\Delta K_{\text {eq,worn }}-\Delta K_{\text {eq,unworn }}}{\Delta K_{\text {eq,worn }}} \times 100 \%$.

It can be seen that, for a crack depth of 0-2 $\mathrm{mm}$, the value of $\Delta K_{\mathrm{eq}}$ calculated for the worn axle is greater than

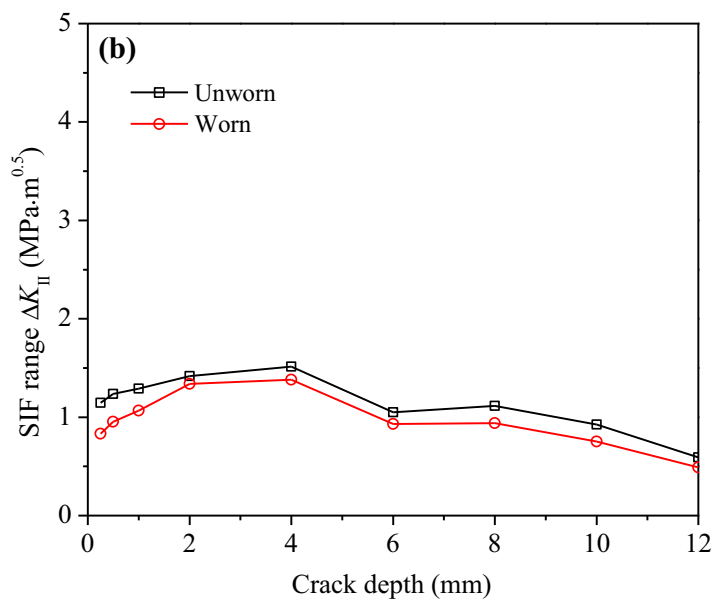

Fig. 21 Evolution of the SIF ranges with crack depth: a $\Delta K_{\mathrm{I}}$ and $\mathbf{b} \Delta K_{\mathrm{II}}$ 


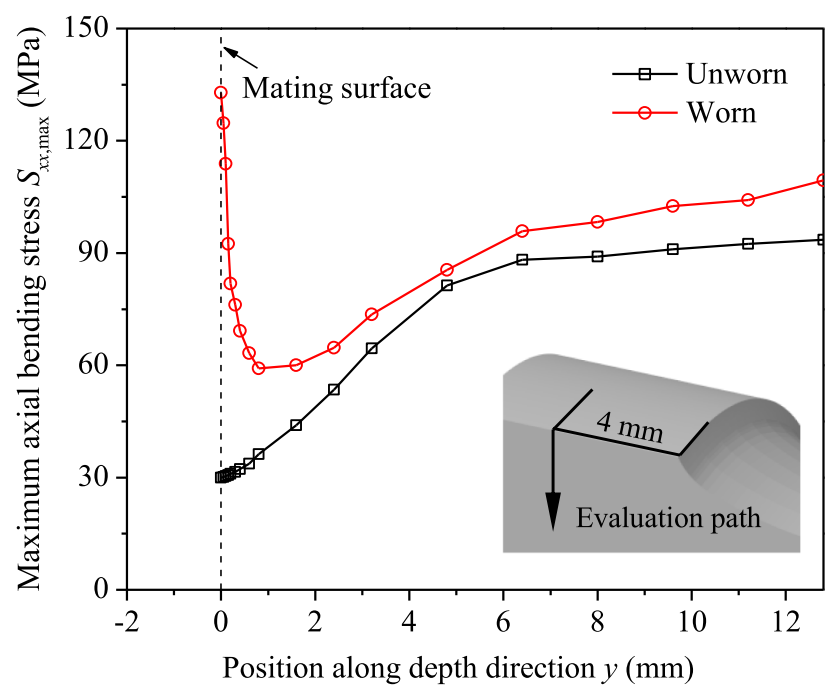

Fig. 22 Distributions of the maximum axial bending stress $S_{x x \text {, max }}$. These stresses were obtained from Models 3 and 4 listed in Table 3

that for the unworn axle. When the crack depth is greater than $2 \mathrm{~mm}$, the difference between the values of $\Delta K_{\mathrm{eq}}$ calculated for the worn/unworn axles is negligible. Furthermore, the relative error $\delta$ decreases with an increase in the crack depth, and $\delta$ is over $5 \%$ when the crack depth is less than $2 \mathrm{~mm}$. This indicates that fretting wear affects the crack propagation when the crack depth is within the region of $0-2 \mathrm{~mm}$, and that without considering the fretting wear, a fretting fatigue crack propagation prediction in the press-fitted region would overestimate the residual life time.

Based on the previous analysis and discussion, it can be concluded that the stress redistribution resulting from fretting wear greatly promotes fretting fatigue crack initiation within the fretted zone, and simultaneously produces a stress field that facilitates fretting fatigue crack

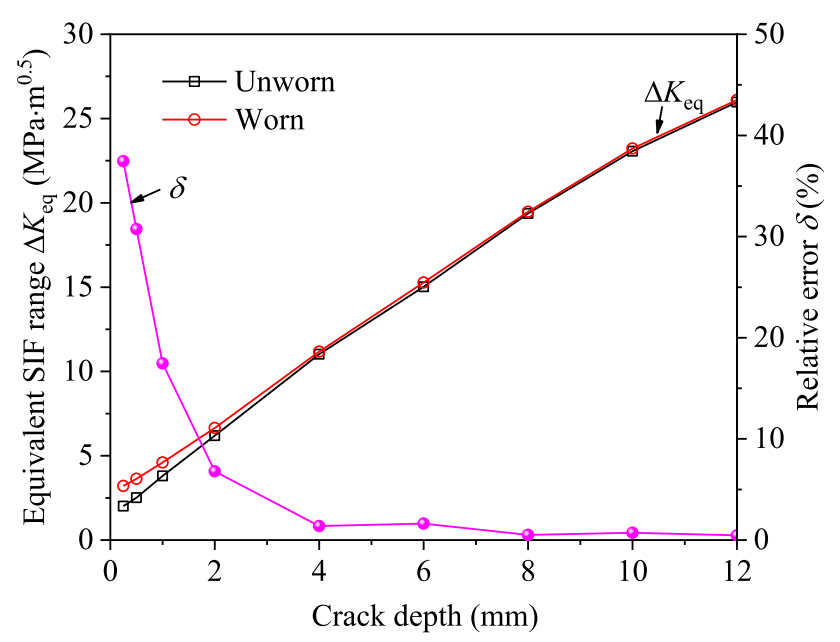

Fig. 23 Evolution of the equivalent SIF range $\Delta K_{\text {eq }}$ and the relative error $\delta$ with crack depth propagation. Under in-service conditions, fretting wear is inevitable for a railway axle, and fretting fatigue occasionally occurs. Therefore, the effect of the stress redistribution resulting from fretting wear is suggested to be taken into account when evaluating the fretting fatigue in railway axles.

\section{Conclusions}

In this study, fatigue tests were conducted on full-scale railway axles, and then the fretting wear and fretting fatigue in the fretted zone of axles were analysed. Based on the experimental results, 3D FE models were established to investigate the effect of fretting wear on the fretting fatigue in full-scale railway axles. The following main conclusions can be drawn:

(1) The fretted zone could be divided into zones I-III according to the surface damage morphologies. The fretting wear mechanisms for the fretted zone included abrasive wear, oxidative wear, and delamination. Fretting wear alleviated the stress concentration near the wheel seat edge and resulted in a new stress concentration near the worn/unworn boundary in zone II, which greatly promoted fretting fatigue crack initiation.

(2) The stress concentration resulting from fretting wear increased the equivalent SIF range $\Delta K_{\mathrm{eq}}$, and thus promoted the propagation of fretting fatigue crack within a region of $0-2 \mathrm{~mm}$ below the mating surface.

(3) The orientation of the initial fretting fatigue crack was approximately $33^{\circ}$ with respect to the depth direction of the test axle, suggesting that the crack propagated in a I-II mixed mode. Because $\Delta K_{\mathrm{I}}$ increased with an increase in the crack depth whilst $\Delta K_{\text {II }}$ remained nearly unchanged, mode I played a more critical role as the crack propagated, which resulted in a decrease in the inclined angle.

(4) The effect of the stress redistribution resulting from fretting wear is suggested to be taken into account when evaluating the fretting fatigue in railway axles.

Acknowledgements This work was supported by the Independent Research Project of the State Key Laboratory of Traction Power (No. 2018TPL_Z01), the National Natural Science Foundation of China (No. 51375406) and the Fundamental Research Funds for the Central Universities (No. 2682018CX68).

Open Access This article is licensed under a Creative Commons Attribution 4.0 International License, which permits use, sharing, adaptation, distribution and reproduction in any medium or format, as long as you give appropriate credit to the original author(s) and the source, provide a link to the Creative Commons licence, and indicate if changes were made. The images or other third party material in this 
article are included in the article's Creative Commons licence, unless indicated otherwise in a credit line to the material. If material is not included in the article's Creative Commons licence and your intended use is not permitted by statutory regulation or exceeds the permitted use, you will need to obtain permission directly from the copyright holder. To view a copy of this licence, visit http://creativecommons. org/licenses/by/4.0/.

\section{References}

1. Maedler K, Geburtig T, Ullrich D (2016) An experimental approach to determining the residual lifetimes of wheelset axles on a full-scale wheel-rail roller test rig. Int J Fatigue 86:58-63

2. Zerbst U, Beretta S, Köhler G, Lawton A, Vormwald M, Beier HT, Klinger C, Černý I, Rudlin J, Heckel T (2013) Safe life and damage tolerance aspects of railway axles-a review. Eng Fract Mech 98(1):214-271

3. Pourheidar A, Regazzi D, Cervello S, Foletti S, Beretta S (2020) Fretting fatigue analysis of full-scale railway axles in presence of artificial micro-notches. Tribol Int 150:106383

4. Zhai W, Han Z, Chen Z, Ling L, Zhu S (2019) Train-track-bridge dynamic interaction: a state-of-the-art review. Veh Syst Dyn 57(7):984-1027

5. Foletti S, Beretta S, Gurer G (2016) Defect acceptability under full-scale fretting fatigue tests for railway axles. Int $\mathrm{J}$ Fatigue 86:34-43

6. Zhu C, He J, Peng J, Ren Y, Lin X, Zhu M (2019) Failure mechanism analysis on railway wheel shaft of power locomotive. Eng Fail Anal 104:25-38

7. Gürer G, Gür CH (2017) Failure analysis of fretting fatigue initiation and growth on railway axle press-fits. Eng. Failure Anal 84:151-166

8. BS EN 13103 (2017) Railway applications-wheelsets and bogies-design method for axles with external journals. BSI, London

9. BS EN 13104-2009 + A2-2012 Railway applications-wheelsets and bogies-powered axles-design method, BSI, London

10. JIS E4501-1995 Railway rolling stock - design methods for strength of axles, JSA, Tokyo

11. Hirakawa K, Toyama K, Kubota M (1998) The analysis and prevention of failure in railway axles. Int $\mathrm{J}$ Fatigue 20(2):135-144

12. Smith RA, Hillmansen S (2004) A brief historical overview of the fatigue of railway axles. Proc Inst Mech Eng Part F: J Rail Rapid Transit 218(4):267-277

13. Zeng D, Zhang Y, Lu L, Zou L, Zhu S (2019) Fretting wear and fatigue in press-fitted railway axle: a simulation study of the influence of stress relief groove. Int J Fatigue 118:225-236

14. Iyer K (2001) Peak contact pressure, cyclic stress amplitudes, contact semi-width and slip amplitude: relative effects on fretting fatigue life. Int J Fatigue 23(3):193-206

15. Song C, Shen MX, Lin XF, Liu DW, Zhu MH (2013) An investigation on rotatory bending fretting fatigue damage of railway axles. Fatigue Fract Eng Mater Struct 37(1):72-84

16. Hattori T, Kawai S, Okamoto N, Sonobe T (1981) Torsional fatigue strength of a shrink fitted shaft. Bull. JSME 24(197):1893-1900

17. Zou L, Zeng D, Wang J, Lu L, Li Y, Zhang Y (2020) Effect of plastic deformation and fretting wear on the fretting fatigue of scaled railway axles. Int J Fatigue 132:105371

18. Zhang Y, Lu L, Gong Y, Zhang J, Zeng D (2017) Fretting wearinduced evolution of surface damage in press-fitted shaft. Wear 384:131-141
19. Zhang Y, Lu L, Gong Y, Zeng D, Zhang J (2017) Finite element modeling and experimental validation of fretting wear scars in press-fitted shaft with open zone. Tribol Trans 61(4):585-595

20. Zhang YB, Lu LT, Zou L, Zeng DF, Zhang JW (2018) Finite element simulation of the influence of fretting wear on fretting crack initiation in press-fitted shaft under rotating bending. Wear 400-401:177-183

21. Ishiduka H, Kubota M, Sakae C, Kondo Y, Sato Y, Makino K (2006) Evaluation of fatigue crack propagation property on the wheelseat of normalized axles for narrow gauge line vehicles. J Soc Mater Sci Jpn 55(6):550-557

22. Martínez JC, Useche LVV, Wahab MA (2017) Numerical prediction of fretting fatigue crack trajectory in a railway axle using XFEM. Int J Fatigue 100:32-49

23. Gutkin R, Alfredsson B (2008) Growth of fretting fatigue cracks in a shrink-fitted joint subjected to rotating bending. Eng Fail Anal 15(5):582-596

24. Ekberg A (2004) Fretting fatigue of railway axles - a review of predictive methods and an outline of a finite element model. Proc Inst Mech Eng Part F: J Rail Rapid Transit 218(4):299-316

25. Erena D, Vázquez J, Navarro C, Talemi R (2020) Numerical study on the influence of artificial internal stress relief groove on fretting fatigue in a shrink-fitted assembly. Tribol Int 151:106443

26. BS EN 13260-2009 Railway applications-wheelsets and bogies-wheelsets-product requirements, BSI, London

27. Cervello S (2016) Fatigue properties of railway axles: new results of full-scale specimens from Euraxles project. Int $\mathrm{J}$ Fatigue $86: 2-12$

28. Makino T, Sakai H, Kozuka C, Yamazaki Y, Yamamoto M, Minoshima K (2020) Overview of fatigue damage evaluation rule for railway axles in Japan and fatigue property of railway axle made of medium carbon steel. Int J Fatigue 132:105361

29. Abaqus User Manual (2014). Abaqus Theory Guide. Version 6.14. USA: Dassault Systemes Simulia Corp

30. Zheng JF, Luo JL, Peng JF, Jin XS (2010) Fretting wear behaviors of a railway axle steel. Tribol Int 43(5):906-911

31. Bertini L, Santus C (2015) Fretting fatigue tests on shrink-fit specimens and investigations into the strength enhancement induced by deep rolling. Int J Fatigue 81:179-190

32. Rajasekaran R, Nowell D (2005) On the finite element analysis of contacting bodies using submodelling. J Strain Anal Eng Des 40(2):95-106

33. Smith KN, Watson P, Topper TH (1970) A stress-strain function for the fatigue of metals. J Mater 5(4):767-778

34. Fatemi A, Socie DF (1988) A critical plane approach to multiaxial fatigue damage including out-of-phase loading. Fatigue Fract Eng Mater Struct 11(3):149-165

35. Luke M, Burdack M, Moroz S, Varfolomeev I (2016) Experimental and numerical study on crack initiation under fretting fatigue loading. Int J Fatigue 86:24-33

36. Sum WS, Williams EJ, Leen SB (2005) Finite element, criticalplane, fatigue life prediction of simple and complex contact configurations. Int J Fatigue 27(4):403-416

37. Makino T, Kato T, Hirakawa K (2011) Review of the fatigue damage tolerance of high-speed railway axles in Japan. Eng Fract Mech 78(5):810-825

38. Wu SC, Xu ZW, Liu YX, Kang GZ, Zhang ZX (2018) On the residual life assessment of high-speed railway axles due to induction hardening. Int J Rail Transp 6(4):218-232

39. Mai SH, Gravouil A, Nguyen-Tajan ML, Trollé B (2017) Numerical simulation of rolling contact fatigue crack growth in rails with the rail bending and the frictional contact. Eng Fract Mech 174:196-206

40. Irwin GR (1958) Fracture mechanics, in the book of structural mechanics. Springer, New York 
41. Keisuke $T$ (1974) Fatigue crack propagation from a crack inclined to the cyclic tensile axis. Eng Fract Mech 6:493-507

42. Richard HA, Buchholz FG, Kullmer G, Schöllmann M (2003) 2D- and 3D- mixed mode fracture criteria. Key Eng Mater 251-252:251-260

43. Richard HA, Schramm B, Schirmeisen NH (2014) Cracks on mixed mode loading - theories, experiments, simulations. Int $\mathrm{J}$ Fatigue 62:93-103

44. Erdogan F, Sih G (1963) On the crack extension in plates under plane loading and transverse shear. J Basic Eng 85(4):519-525
45. Sajith S, Murthy KSRK, Robi PS (2020) Experimental and numerical investigation of mixed mode fatigue crack growth models in aluminum 6061-T6. Int J Fatigue 130:105285

46. Alshoaibi AM, Fageehi YA (2020) 2D finite element simulation of mixed mode fatigue crack propagation for CTS specimen. J Mater Res Technol 9(4):7850-7861

47. Richard H, Fulland M, Sander M (2005) Theoretical crack path prediction. Fatigue Fract Eng Mater Struct 28(1-2):3-12 